\title{
Dynamic characterization of the hill of Civita di Bagnoregio (Viterbo, Central Italy) for seismic response analysis
}

\author{
Michele Cercato $^{\mathrm{a}, *}$, Giorgio De Donno ${ }^{\mathrm{a}}$, Anita Di Giulio ${ }^{\mathrm{b}}$, Giuseppe Lanzo ${ }^{\mathrm{c}}$, Paolo Tommasi ${ }^{\mathrm{b}}$ \\ a "Sapienza" University of Rome - DICEA, Via Eudossiana 18 - 00184, Rome, Italy \\ ${ }^{\mathrm{b}} \mathrm{CNR}$ - Institute for Environmental Geology and Geo-Engineering, Rome, Italy \\ c "Sapienza" University of Rome - DISG, Via A. Gramsci 53 - 00197, Rome, Italy
}

\section{A R T I C L E I N F O}

\section{Keywords:}

Seismic site effects

Dynamic properties

Surface geophysics

Downhole

Laboratory testing

Dynamic properties

\begin{abstract}
A B S T R A C T
Located on the top of a volcanic butte, Civita di Bagnoregio is one of the most beautiful villages in Central Italy. This hamlet, which dates back to the Etruscan era, is a medieval cluster of enchanting beauty and a massive tourist attraction that counted more than six hundred thousand visitors in 2016. The peculiar combination of geological conditions, regional seismicity, and the impressive touristic flow caused the city to be listed among the 100 World's most endangered sites.

The definition of a reliable geophysical and geotechnical model of the subsurface is essential for any quantitative evaluation of seismic hazard, which is the key for knowledge-based decisions to design the proper stabilization measures in order to preserve the historical centre. Several geophysical techniques (ambient noise recordings, surface wave methods, electrical resistivity tomography and seismic downhole) were performed to assess the geometry and the low-strain stiffness properties of the different geological units and to provide continuous subsurface imaging throughout the urbanized area. The surface geophysical investigations were complemented by borehole seismics and geotechnical laboratory testing to provide a detailed dynamic/cyclic characterization of the lithotypes, which was used for investigating seismic site effects.

The integration of different investigation techniques allowed circumvention of logistic limitations imposed by the historical center, which are a potential source of over-simplified earthquake engineering models with no or limited experimentally-determined seismic properties, thus resulting in unrealistic seismic response estimates. The investigation approach used in this case study can be extended to historical centers with similar geotechnical conditions to enhance the safety and resilience as a common basis for a sustainable future.
\end{abstract}

\section{Introduction}

One of the key steps in seismic microzonation is the definition of a reliable model of the subsurface for seismic response analysis. This model results from the integration of the geological model (geometry, layering and lithology) and a thorough dynamic characterization of the geological units. Building a model for seismic response analyses below historical centers is very challenging from the engineering seismology's point of view: the ground conditions are often poorly known and the logistic constraints may be severe, especially when the urban center is built on steep topography and the urban fabric is tight. This is a common scenario in Central Italy (Costanzo et al., 2007; Cardarelli et al., 2008) where several historical centers were built in dominant positions for military defense and security reasons, enhancing over the centuries the exposure to landslide and seismic hazard.
Civita di Bagnoregio (Viterbo, Central Italy) is a rather impressive example of this scenario. This medieval hamlet of Etruscan origin is built on top of a sharp butte formed by a slab of soft pyroclastic rocks superimposed to a stiff clay base in the shape of a truncated elliptical cone (Fig. 1a). Civita is known as the "dying city" because the butte is affected by a severe erosive process causing frequent landslides in the clay slope and at the margin of the butte. Over the centuries, landslides have progressively reduced the original built-up area and, in turn, the resident community, which now counts 10 people only. The city is also located in a seismically active area and was severely damaged by the earthquake occurred on June 11, 1695 (Mw 5.8, MCS Intensity IX-X degree) whose epicenter was located in Bagnoregio (the town facing Civita). The seismic event caused 37 fatalities and 61 people injured with devastation in Civita, which at the time counted some 3000 people. In the following centuries, several local and far seismic events affected the historical

\footnotetext{
* Corresponding author.

E-mail address: michele.cercato@uniroma1.it (M. Cercato).
} 
(a)

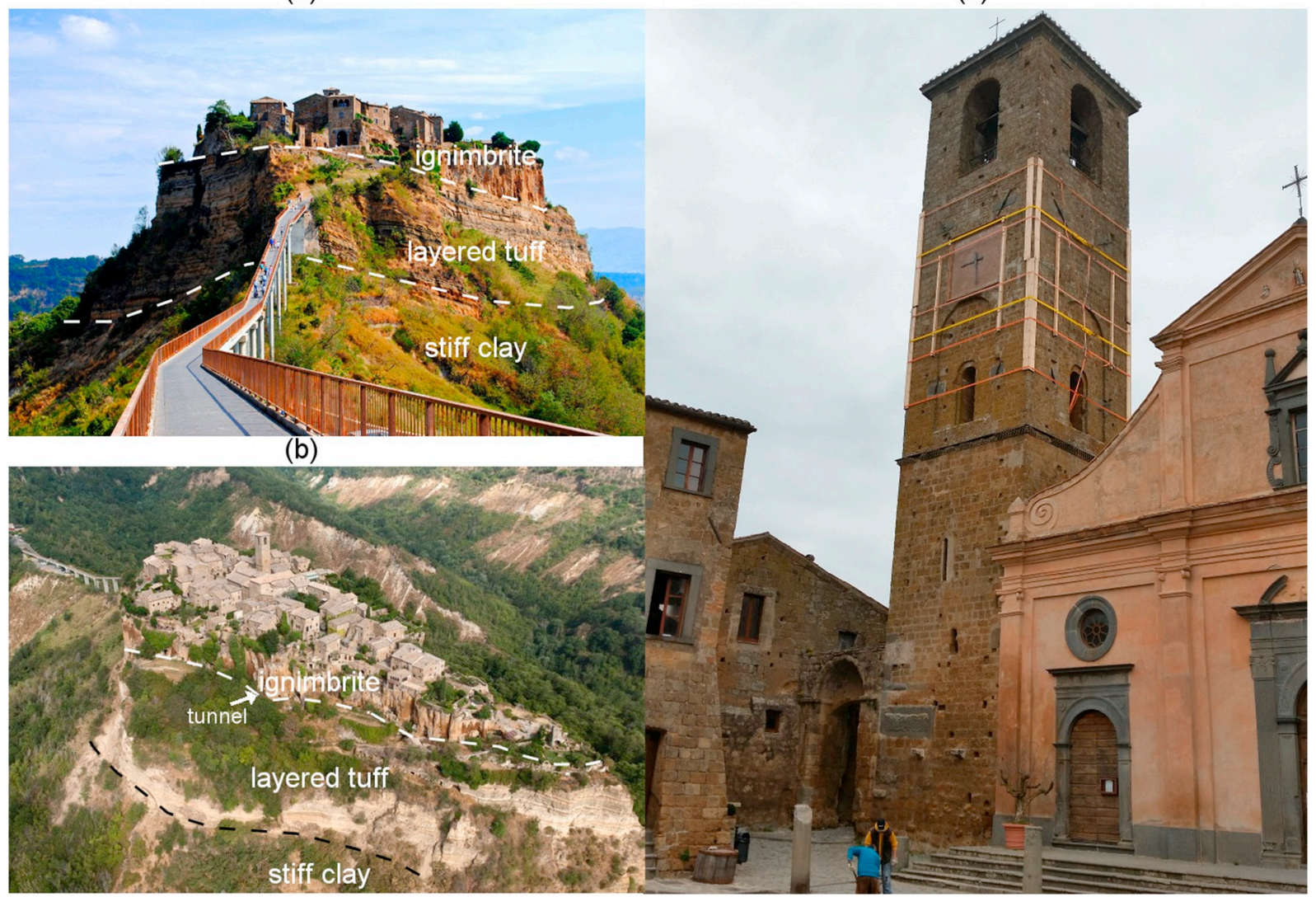

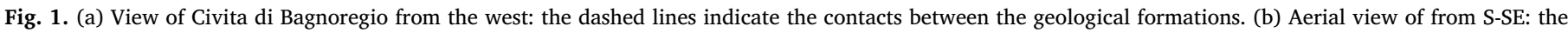

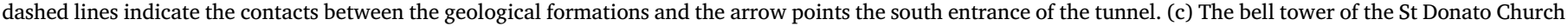
in the centre of Civita di Bagnoregio, damaged after the seismic sequence of Central Italy (2016-2017).

center up to a VIII degree MCS intensity. Recently, on October 30, 2016, an earthquake (Mw 6.6) with epicenter in Norcia, about $80 \mathrm{~km}$ East of Civita, caused damage to the bell tower of the San Donato Church in the main square of Civita (Piazza San Donato).

The peculiar combination of geological conditions, regional seismicity, and the impressive touristic flow, caused this small town to be listed among the 100 World's most endangered sites. Knowledge-based decisions are needed to preserve the historical centre and enhance its resiliency to landslide and seismic hazard in order to endure the safety of human lives (visitors and residents) and buildings. This site poses major challenges for its geological, artistic and logistic features, which require multi-disciplinary investigations to define a quantitative geotechnical and geophysical model of the whole hill, with detailed dynamic characterization of the geological formations. A reliable reconstruction of geometry, succession and physical-mechanical properties of the lithotypes is pivotal not only for seismic response analysis but also for landslide hazard assessment.

The seismic characterization of such a complex environment requires a combination of non-invasive techniques and direct testing (e.g. surface geophysics and borehole) that provide a parametric model of the subsurface oriented to seismic response analysis (e.g. investigating longitudinal, share and surface waves, as well as electrical properties), where the integrated analysis of different parameters can provide enhanced resolution and robustness of the models.

Among the seismic techniques, surface wave methods (Socco and Strobbia, 2004) including Multichannel Analysis of Surface Waves (MASW) have gained increasing attention for the estimation of the Swave profile for geotechnical applications (Park, 2013).

Beside the active seismic methods, during last decades many researchers have tried to explore potential and limits of passive methods for seismic characterization (Bonnefoy-Claudet et al., 2006). In this respect, the ambient-noise recording is a very low budget technique, even though its applicability in urban areas strongly depends on sitespecific conditions. For a simple geological framework, the correlation between resonant frequency of the horizontal-to-vertical (H/V) components of the recorded noise and bedrock depth can be straightforward (Nakamura, 1989; Lane et al., 2008).

Electrical methods, such as Electrical Resistivity Tomography (ERT) can be complementary to surface seismic for the characterization of the shallow subsoil and the anthropogenic environment (e.g. Samouëlian et al., 2005) because the electrical resistivity can be directly linked to changes in soil mineralogy and saturation. This technique is a low budget diagnostic tool for enhancing contacts between different materials, though with a decreasing resolution with depth. Where it is integrated with seismic techniques, it is possible to reduce the uncertainty on the geological layering and to provide a multi-parameter model of the subsurface (e.g. Cardarelli et al., 2014a, 2014b). In light of this, the integration of more than a single surface geophysical method is often helpful in reducing the degree of uncertainty of the geophysical reconstruction. For example, the integration of non-invasive seismic techniques is capable to return a picture of the main geometrical features of the subsoil and a further characterization of the soil stiffness at low strain as far as seismic velocities are concerned. The diagnostic capability of each geophysical method can help to: i) define the in situ low-strain elastic parameters of the geophysical-geotechnical model from direct measurements, which are far more accurate and scientifically sound than those derived from empirical correlation; ii) return a comprehensive image of the subsurface, down to the maximum depth of investigation, enhancing also lateral variations of selected parameters if a tomographic method is employed (ERT in this case); iii) reduce the 
(a)

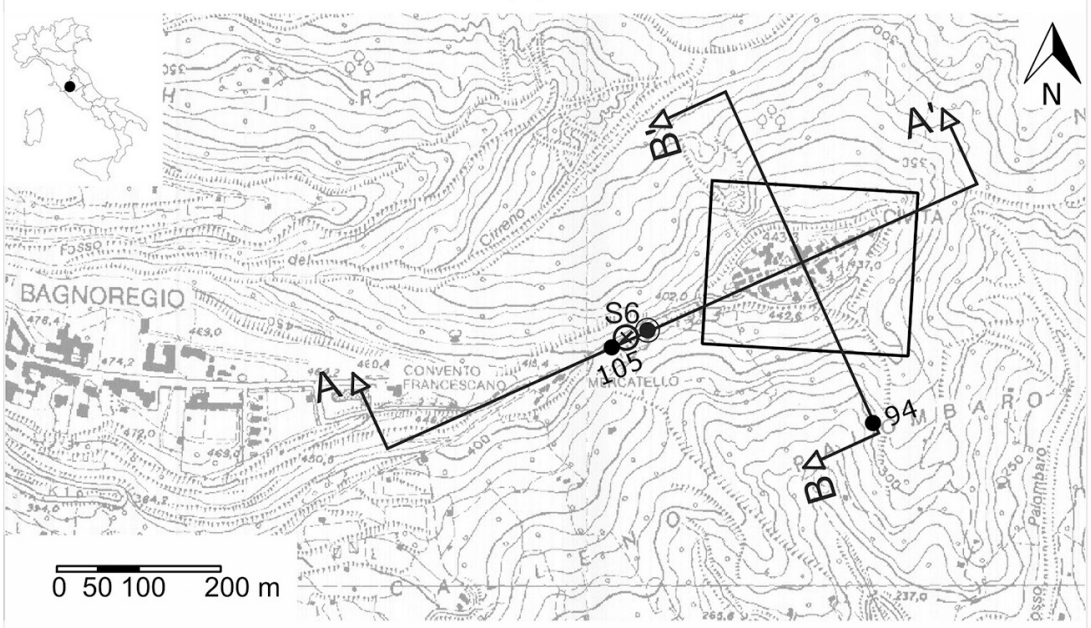

(b)

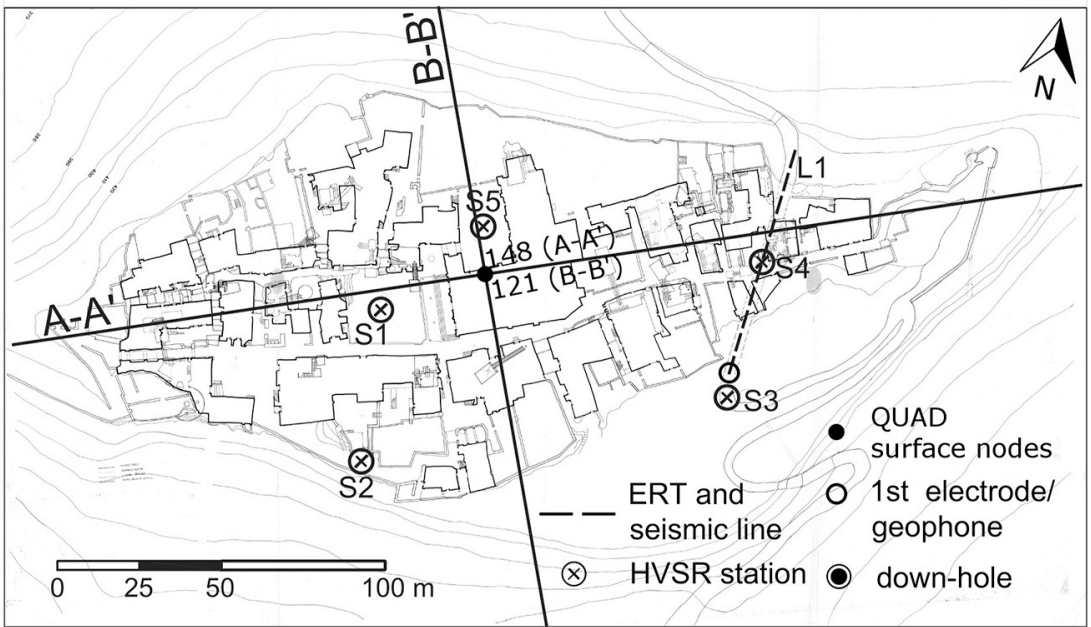

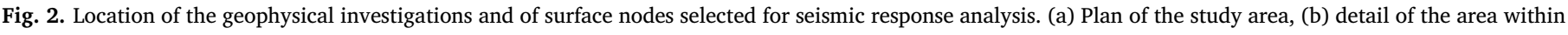
the black rectangle in Fig. 2a. The geological cross-sections A-A' and B-B' are shown in Fig. 3.

ambiguity in defining the final geophysical and geotechnical model by complementing the advantages of different techniques (e.g. ERT and MASW); iv) give a preliminary outline of the resonant frequency using a non-invasive and low-impact method, such as ambient-noise recording.

It is well known that extensive dynamic laboratory testing is always needed to fully characterize the dynamic behavior of the geological units. Previous geotechnical investigations performed on the materials forming the pyroclastic slab and the underlying clay formation included only static tests (Cevolani et al., 1990; Napoleoni, 1991; Iacurto and Priori, 1995; Sciotti et al., 1997; Garbin et al., 2013). Therefore, laboratory measurements were carried out on both the clayey and volcanic formations, in order to investigate the dynamic/cyclic properties of the materials.

Our goal is to combine passive and active geophysical methods and geotechnical laboratory tests for reducing the uncertainty in the definition of a geophysical and geotechnical model for siteswhere accessibility is limited and investigations are not sufficiently detailed, as is the case of Civita di Bagnoregio. The subsoil model is then used for a seismic site response assessment, which should lead to a knowledge - based choice and design of the stabilization measures, to preserve the historical centre and ensure the safety of buildings, visitors and residents. A number of studies, kicked off by the projects for rehabilitation of Civita and the stabilization of the butte slopes, have been conducted since the 90's (e.g. Sciotti et al., 1997). In spite of this research and design activity, until present a unitary view of the preservation problem has been lacking, even regarding the geotechnical aspects alone.

This study, carried out within a research project funded by "Sapienza" University of Rome, aims at combining social aspects of the evolution of Civita di Bagnoregio (including a sustainable touristic exploitation) and preservation issues. With respect to the latter, the present study contributes to fill the gap in the geophysical and geotechnical model to be used in seismic risk assessment.

\section{Site description and geological setting}

Civita di Bagnoregio is a middle-age village rising on top of a butte of Quaternary pyroclastic rocks overlying a plio-pleisotcenic stiff clay formation, located to the east of the plateaux formed by the products of the Vulsini volcanic district, from which it was isolated by a deep erosion (Fig. 1a and b). A thin saddle, which as of today is entirely carved into the clay formation, joins the base of the butte to the base of the volcanic plateau. A slender pedestrian reinforced-concrete bridge, founded on the clayey saddle, connects Civita to the edge of the volcanic plateau and hence to the town of Bagnoregio. According to Margottini (1988), between 1765 and 1984 the saddle was partially dismantled by the erosion, which wasted some $35 \mathrm{~m}$ of pyroclastites and clays.

The continuous landslides at the slab margins and in the underlying clay slope have progressively involved the built-up area on top of the 
butte and thinned the saddle, thus repeatedly damaging the bridge, which was eventually reconstructed in the 60's.

The recent seismic sequence of Central Italy (2016-2017) caused damages to the bell tower of the Church of Saint Donato, the main church in Civita as well as little damages scattered within the hamlet (Fig. 1c).

The butte is formed on by a 10 to $25 \mathrm{~m}$ thick slab of ignimbrite (Ignimbrite di Orvieto-Bagnoregio formation, IOB), overlying a 35 to $55 \mathrm{~m}$ thick layer of thinly stratified pyroclastites (Paleo-Vulsini Formation, $P V F)$ (Nappi et al., 1998). The succession of volcanic materials lies on Pliocenic clays, outcropping on the valley sides (Fig. 1) (Chiani-Tevere Formation, CTF) (Mancini et al., 2004) and underlying many volcanic buttes in the region.

The pyroclastic slab at the top of the hill, delimited by vertical cliffs, is leaf-shaped with a maximum axis of $350 \mathrm{~m}$ oriented WSW-ENE and a minimum axis of $120 \mathrm{~m}$ oriented NNW-SSE. Its thickness varies along the major axis from $45 \mathrm{~m}$ at the western and eastern edges to $70 \mathrm{~m}$ in the central-eastern part (Fig. 2 and 3).

At the top of the clay formation, a thin layer of silty sands is also found. The thickness of the clay unit and hence the depth of the MesoCenozoic bedrock (sandstones and shales) with respect to the claypyroclastite contact is $>200 \mathrm{~m}$, according to Mancini et al. (2004).

At Civita, the $I O B$ is a massive rock-like red tuff, very similar to that forming many buttes and mesas in the region (Sciotti, 1980). The ignimbrite is characterized by large black scoriae, pumices, lithic fragment and small crystals interspersed within a glassy ground mass. In the rock-like facies of the formation, i.e. the only present at Civita, the ground mass is largely zeolitized (Tommasi and Ribacchi, 1998; Cappelletti et al., 1999). Inside the rock slab the ignimbrite is moderately jointed (joint spacing larger than three metres). Only behind the cliff, joints induced by the deformation of the clay substratum are more frequent and subdivide the rock mass into columns even 1-2 m wide.

The $P V F$ consists of alternating 0.2 to $1 \mathrm{~m}$-thick layers of fall-out products varying in grain size composition, bonding degree and alteration conditions. The most frequent lithotypes (layers) are: i) a mixture of fine-and coarse-grained ashes (FA); ii) coarse-grained ashes (CA), mostly small pumices; iii) lapilli (L), mostly pumices and iv) paleosol (P) layers, similar to FA. Fine ash layers are frequently cemented whilst layers of coarse-grained ashes and lapilli are loose or slightly cemented. Paleosols likely result from alteration of fine ash layers.

According to Sciotti et al. (1997) the thickness of the volcanic slab (and consequently the depth of the clay formation below the town), is variable along the WSW-ENE direction (A-A' section, Fig. 3a), while it is approximately constant along the normal direction (B- $\mathrm{B}^{\prime}$ section,
Table 1

Acquisition parameters for the electrical and seismic (surface and downhole) investigations.

\begin{tabular}{|c|c|}
\hline Survey & Acquisition details \\
\hline Ambient-noise recording & $\begin{array}{l}\text { Sensor: Sara SS02 3C geophone } 0.2 \mathrm{~Hz} \\
\text { Recording window: } 45 \mathrm{~min} \\
\text { Device: 3-channel Sara SL06 seismograph } \\
\text { Sampling frequency: } 100 \mathrm{~Hz}\end{array}$ \\
\hline $\begin{array}{l}\text { Electrical resistivity } \\
\text { tomography }\end{array}$ & $\begin{array}{l}\text { Electrodes: } 48 \text { steel electrodes } 1.5 \mathrm{~m} \text { spaced } \\
\text { Arrays: Dipole-dipole, Multiple gradient and } \\
\text { Wenner-Schlumberger } \\
\text { Device: Resistivimeter Iris Instruments SyscalPro } 48 \\
\text { Number of quadrupoles: } 4143\end{array}$ \\
\hline Downhole (P- and S-wave) & $\begin{array}{l}\text { Borehole depth: } 30 \mathrm{~m} \\
\text { Geophone: 3-component Geostuff BHG-2 (14 Hz) } \\
\text { Depth interval: } 1 \mathrm{~m} \\
\text { Sources: } 7 \mathrm{~kg} \text { hammer weight stricken on an iron } \\
\text { base plate (P-wave) or on a lightweight aluminum } \\
\text { source block (S-wave) } \\
\text { Device: seismograph Geode Geometrics 24-channel } \\
\text { Sampling interval: } 31.2 \mu \mathrm{s}\end{array}$ \\
\hline $\begin{array}{l}\text { Multichannel analysis of } \\
\text { surface waves }\end{array}$ & $\begin{array}{l}\text { Geophones: } 24 \text { vertical geophones }(4.5 \mathrm{~Hz}) \\
24 \text { horizontal geophones }(8 \mathrm{~Hz}) \\
\text { Geophone spacing: } 3 \mathrm{~m} \\
\text { Sources: same as Downhole above. } \\
\text { Number of shots: } 7 \text { shots symmetric } \\
\text { Device: } 2 \text { seismographs Geode Geometrics } 48 \text { - } \\
\text { channel } \\
\text { Sampling interval: } 125 \mu \mathrm{s} \\
\text { Trace length: } 2.048 \mathrm{~s}\end{array}$ \\
\hline
\end{tabular}

Fig. 3b). They supposed that the slope of the contact between the two formations is steeper in the middle-eastern zone of the A- $\mathrm{A}^{\prime}$ section, where a tunnel ( $65 \mathrm{~m}$ long, $2 \mathrm{~m}$ wide and $2 \mathrm{~m}$ high), was excavated few meters below the IOB-PVF contact by widening an old Etruscan aqueduct. However, we set the interface between $P V F$ and CTF formations through the aid of an aerial view (Fig. 1b), which clearly shows the tuffclay discontinuity in the middle part of the town.

\section{Experimental data acquisition and processing}

\subsection{Geophysical field measurements}

The location of the geophysical survey is indicated in Fig. 2, whereas the parameters employed for field data acquisition are reported in Table 1 . The surface geophysical campaign included passive (six ambientnoise recordings) and active (ERT and MASW) geophysical methods, the

(a)
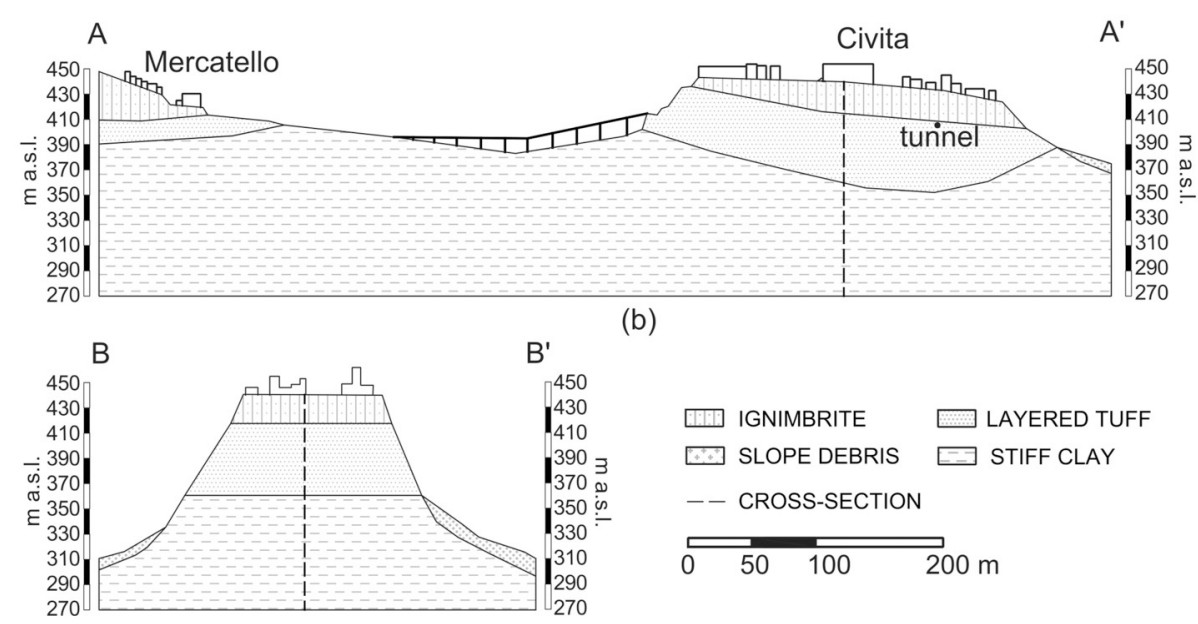

(b)

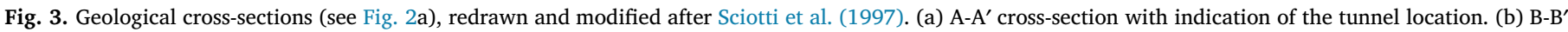
cross-section. 
(a)

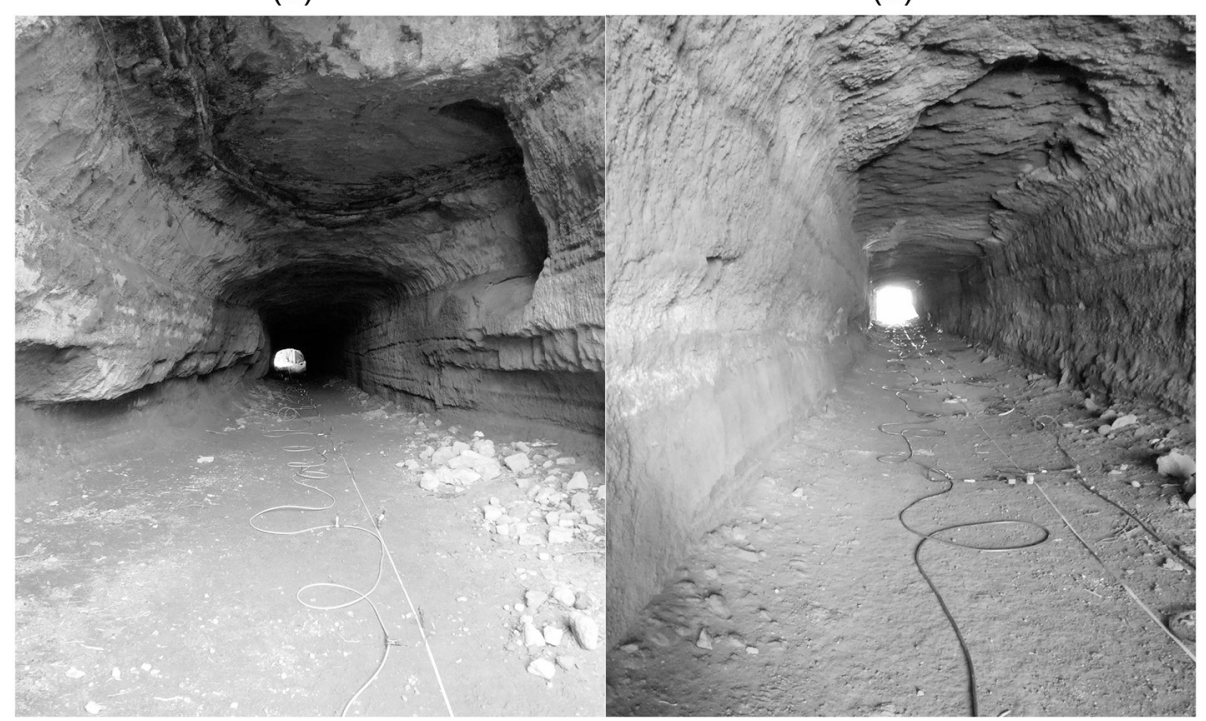

Fig. 4. Location of (a) ERT and (b) seismic data acquisition within the tunnel.

latter were applied along a single line (L1) running at the tunnel floor (405 $\mathrm{m}$ a.s.1.) (Fig. 2b). A single downhole investigation was performed in a borehole drilled into the clay saddle, under the bridge (Fig. 2a).

Six ambient-noise recording stations were located throughout the town (S1, S2, S5), alongside the electrical and seismic lines (S3-S4) and close to the down-hole investigation (S6, Mercatello village), as shown in Fig. 2. The selected sites are accessible spots not overlying underground levels and basement cellars. We used a three-component Sara seismic sensor with natural period of $5 \mathrm{~s}$ operating within a recording window of $45 \mathrm{~min}$ using a sampling frequency of $100 \mathrm{~Hz}$. Time alignment of samples and positioning were guaranteed by a GPS system. All seismic records were processed with the Geopsy software (www.geopsy.org) using the standard parameters suggested by the SESAME Project (2004).

Two-dimensional ERT data were acquired (Fig. 4a) by using an array of 48 stainless steel electrodes spaced $1.5 \mathrm{~m}$ apart, connected to an IRIS Instruments SyscalPro48 resistivimeter. We used a combination of dipole-dipole (maximum dipole length $a_{\max }=5$ and maximum dipole separation $n_{\max }=6$ ), multiple gradient ( $a_{\max }=5$ and maximum separation factor $\left.s_{\max }=18\right)$ and Wenner-Schlumberger $\left(a_{\max }=5\right.$ and $n_{\max }=6$ ) configurations. These arrays combine a robust signal with satisfying resolution in both directions and good depth of investigation (Dahlin and Zhou, 2004). The ensemble of ERT measurements (4143 quadrupoles) was inverted using the VEMI algorithm (De Donno and Cardarelli, 2017). No preliminary assumptions on the soil layering were used to constrain the inversion process.

We performed a multi-component MASW investigation employing 24 vertical geophones $(4.5 \mathrm{~Hz})$ and 24 horizontal geophones $(8 \mathrm{~Hz})$ oriented according to the transverse component.

This layout was set was to record both Rayleigh and Love wave data employing a 7-kg sledgehammer stricken vertically on a metal plate for generating Rayleigh-waves and horizontally on a lightweight aluminum source in opposite direction.

The seismic data, after trace balancing and amplitude spreading correction, are transformed into the $f-c$ (frequency-phase velocity) domain via the phase-shift method (Park et al., 1999) and the observed dispersion is inverted as fundamental mode data employing the heuristic algorithm described by Cercato et al. (2010) and Cercato (2011). The energy function $E$ selected for the simulated annealing inversion is:

$E=\sqrt{\frac{1}{N} \sum_{j=1}^{N} \frac{\left(d_{j}^{\text {pre }}-d_{j}^{\text {obs }}\right)^{2}}{\sigma_{j}^{2}}}$, where $N$ is the number of experimental points, $d_{j}^{\text {pre }}$ and $d_{j}^{o b s}$ are the $j$-th predicted and observed dispersion values and $\sigma_{j}$ is the experimental standard deviation associated to $d_{j}^{o b s}$, respectively.

A seismic downhole survey was carried out under the bridge (see Fig. 2a for location, elevation around $385 \mathrm{~m}$. a.s.l.) to measure the seismic velocity of the clay formation, using the same sources as for MASW. Two shots in opposite directions were executed for each geophone location to enhance the picking accuracy of the S-wave arrival by phase difference. The $14-\mathrm{Hz}$ three-component geophone, lowered into the hole at depth interval of $1 \mathrm{~m}$, was oriented by an embedded magnetic compass for maximizing the amplitude of the S-wave on the transverse component of the receiver. The picked traveltimes $t^{o b s}$ were uncoupledly inverted for P- and S-waves using a simulated annealing algorithm with the energy function described in (1), where $N$ is the number of receiver locations and $d_{j}^{\text {pre }}$ and $d_{j}^{\text {obs }}$ are, respectively, the $j$-th predicted and observed traveltimes computed employing a 1D layered model and the observed traveltimes were used as weighting factor instead of $\sigma_{j}$. In the inversion of the downhole traveltimes, only the seismic velocities are allowed to vary and the layer thicknesses are held fixed.

\subsection{Laboratory investigations}

Laboratory tests were carried out on specimens of clay and layered pyroclastites, while the dynamic properties of the ignimbrite were inferred from laboratory tests conducted on borehole specimens retrieved at Orvieto on the red massive tuff of the $I O B$ (Tommasi and Ribacchi, 1998; Verrucci et al., 2015). The undisturbed clay samples were retrieved with a Dennison sampler in the same borehole used for downhole investigations. Tests on different materials forming the $P V F$ were carried out on specimens retrieved from undisturbed block samples taken from cuts and in the tunnel (Fig. 4). Values refer to specimens with porosity comparable to that measured on specimens from Civita.

Dynamic/cyclic properties were obtained for both formations (clay and layered pyroclastites) from the measurement of ultrasonic pulse velocity (UPV), dynamic resonant column tests (RC), cyclic simple shear (DSDSS) and torsional shear (TS) tests. On the paleosol all kind of tests were conducted, whilst the FA and CA lithotypes were subjected only to a single DSDSS undisturbed specimen and a RC/TS test on a reconstituted specimen, respectively, due to difficulties encountered in specimen preparation. Tests conducted on the different materials are reported in Table 2.

For measuring P- and S-wave velocities, a square-wave ultrasonic pulse was generated with a CNS-PUNDIT device. On $P V F$ and CTF a pair 
Table 2

Laboratory tests performed on the different materials.

\begin{tabular}{lllllll}
\hline & Ignimbrite & Cemented fine ash & Coarse ash & Lapilli & Paleosol & Clay \\
\hline UPV & $\times$ & $\times$ & $\times$ & - & $\times$ & $\times$ \\
DSDSS & - & $\times$ & - & - & $\times$ & $\times$ \\
RC & $\times$ & - & $\times$ & - & $\times$ & $\times$ \\
TS & $\times$ & - & $\times$ & - & $\times$ & $\times$ \\
\hline
\end{tabular}

of Panametrics piezoelectric transducers (diameter $=30 \mathrm{~mm}$, natural frequency $=500 \mathrm{kHz}$ ) was used. The signal, amplified with a gain of $60 \mathrm{~dB}$, was analysed with a digital oscilloscope. On CA and CP materials, specimens-transducer coupling was improved by applying on the ends a $0.5 \mathrm{~mm}$-thick plaster layer. On $I O B$, measurements were conducted under uniaxial compression conditions at low values of axial stress ( $<0.1 \mathrm{MPa}$ ) with CNS $500 \mathrm{kHz}$ transducers having a diameter of $54 \mathrm{~mm}$. A film of cane molasses was applied between transducers and specimen ends.

The DSDSS apparatus is described in D'Elia et al. (2003). Possible minor false deformations due to some slip at the specimen-cap interface were minimised by using stainless steel caps and by sticking the specimen ends to the caps with an epoxy adhesive. Owing to the stiffness of the materials and to the unavoidable although extremely thin, annular gap between the lateral surface of the cored specimens and the membrane, the lateral constraint cannot be completely achieved by such a method. Nevertheless, a significant horizontal confinement is applied at the end faces, which are firmly fixed to the caps, especially for very short specimens.

Torsional shear (TS) and resonant column (RC) tests were conducted with a device derived from the first free-fixed type machine designed at the University of Texas at Austin (Isenhower, 1979). The specimen ends for the TS-RC tests were also stuck to the platens with epoxy adhesive, thus ensuring full compliance. The specimen was subjected to an isotropic pressure $p$.

\section{Results}

\subsection{Geophysical field measurements}

The $\mathrm{H} / \mathrm{V}$ spectra for the six ambient-noise recording stations are reported in Fig. 5, where the amplitude of the $\mathrm{H} / \mathrm{V}$ spectral ratio is plotted as a function of frequency. The S1 and S4 spectra present a single peak around $1 \mathrm{~Hz}$ corresponding to a spectral ratio of 3-3.5. A similar peak can be recognized also on the S2, S3 and S5 spectra, even though a secondary peak is clearly visible at a slightly higher frequency $(1.4 \mathrm{~Hz})$. The secondary peak becomes predominant at the S3 station, while similar HVSR values can be attributed to the two frequencies for the $\mathrm{S} 2$ and $\mathrm{S} 5$ recordings.

The S6 station, acquired under the bridge on outcropping clay, shows a relatively flat spectrum with a peak at $4.5 \mathrm{~Hz}$, likely due to the bridge. In some stations (S2, S4, S5 and S6) a low-frequency minor peak appears $(0.65 \mathrm{~Hz})$ likely due to the presence of the deep bedrock. Overall, the shape of the HVSR spectra the number of peaks and the maximum amplification vary as a function of the relative location within the town. This could be due to the peculiar morphology and to the variable thickness of the volcanic slab.

The result of ERT inversion, shown in Fig. 6, highlights a three-layer model of the subsoil down to $15 \mathrm{~m}$ from the tunnel's surface, where the interfaces between different layers could be assumed as horizontal. The model's overall goodness-of-fit is confirmed by the low RMSE at the last iteration $(0.89 \%)$. The model is characterized by a shallow resistive layer (depth $=0-2 \mathrm{~m}$, resistivity $=20-50 \Omega \mathrm{m}$ ), with thin conductive intercalations retrieved in surface proximity only at the boundaries $(x=0-15 \mathrm{~m}$ and $35-70 \mathrm{~m})$. Then, resistivity decreases $(5-10 \Omega \mathrm{m})$ down to a depth of $10 \mathrm{~m}$, where a further resistivity increase (50-200 $\Omega \mathrm{m}$ ) occurs. Since the clay layer should be visible according to the preliminary geological information (Fig. 2) as a low-resistivity unit at greater depths (lower than the maximum model depth equal to $390 \mathrm{~m}$ a.s.1. - $15 \mathrm{~m}$ from the tunnel floor), the ERT is not able to reach the clayey substratum but only to enlighten the transitions between different facies of the stratified pyroclastites. According to Fig. 6, the high heterogeneity of the stratified pyroclastites results in variations of the elastic properties, that MASW investigations should properly address.

The acquisition geometry allowed to record both Rayleigh and Love waves. Unfortunately, the Love-wave seismograms did not carry enough low frequency to be useful to retrieve an S-wave profile, due to the short wavelength of the signal, so that our interpretation is restricted to the vertical component only (Rayleigh). Nevertheless, the interpretation of S-wave arrivals on the transverse component allowed a proper estimation of the S-wave velocity of the first seismic layer.

In principle, especially in the case of shear velocity inversions and/or high stiffness contrasts within the soil column (Cercato et al., 2010), higher modes may propagate with more energy than the fundamental mode and become dominant over specific frequency ranges. The thin layering of the pyroclastites is responsible for a scattered pattern of the observed dispersion, with several thin velocity inversion along the profile. Nevertheless, the fundamental mode is always clearly visible and the independent data confirmed that the phase velocity at high frequency is related to the true Swave layer velocity as assessed using SH-wave refraction.

Because of the velocity inversion in the shear-wave profile, only the direct S-wave arrival could be picked on the recorded SH seismograms and are not shown here. This was important to constrain our interpretation to the fundamental mode only of the Rayleigh waves. Nevertheless, to confirm the results of our inversion, we performed a posteriori-full waveform modelling of the solution using the reflectivity method, to confirm that the fundamental mode is clearly observed in our experiment.

An example $f$-c panel from MASW investigation is shown in Fig. 7a, while the inverted minimum-misfit model is shown in Fig. $7 \mathrm{~b}$ and the $f-c$ analysis results obtained by considering the a posteriori full-waveform modelling associated to the minimum misfit model is displayed in Fig. 7c and compared to the observed phase velocity. The seismic velocities retrieved from the inversion falls within the range $220-680 \mathrm{~m} / \mathrm{s}$, thus confirming the substantial heterogeneity of the layered pyroclastites.

The raw seismic records from $\mathrm{DH}$ investigation are reported in Fig. $8 \mathrm{a}$ and $\mathrm{b}$ for $\mathrm{P}$ - and S-wave respectively. The inverted velocity profiles does not exhibit particularly strong velocity contrasts (Fig. 8c) except for the very shallow layers, which have suffered softening and alteration (Garbin et al., 2013). Both the inverted velocity profiles do not show a clear velocity-depth trend. The maximum velocity values are about 2300 and $440 \mathrm{~m} / \mathrm{s}$ for P- and S-waves, respectively, measured between 20 and $27 \mathrm{~m}$ of depth (around $360 \mathrm{~m}$ a.s.l.). To assess more precisely the velocities of the clay formation in the lower part of the borehole, we reduced the spacing between the receiver stations to $0.5 \mathrm{~m}$ to estimate the seismic velocities over an increased number of measurements per layer. The variations of the seismic velocities are more prominent in the P-wave profile and are consistent the accuracy for the picking traveltimes.

\subsection{Laboratory investigations}

\subsubsection{Ignimbrite (IOB)}

The ignimbrite is a high-porosity soft rock, which at Civita is characterized by a porosity $n$ of $45-50 \%$ and a uniaxial compression strength in the range 11-18 MPa (Iacurto and Priori, 1995). The widespread zeolitization gives the ignimbrite higher strength and stiffness with respect to the non-zeolitized pyroclastic flow deposits recognized within the $I O B$ at other sites (Tommasi et al., 2015). Zeolitization also reduces the density of the solid phase $\rho_{s}$ and hence the bulk density $\rho$ of the ignimbrite (Table 3). Consequently, acoustic impedance of the ignimbrite is significantly lower than that of non-zeolitized pyroclastites with similar stiffness. Results of tests on the Orvieto ignimbrite specimens are reported in Table 3 and Fig. 9a. 
(a)

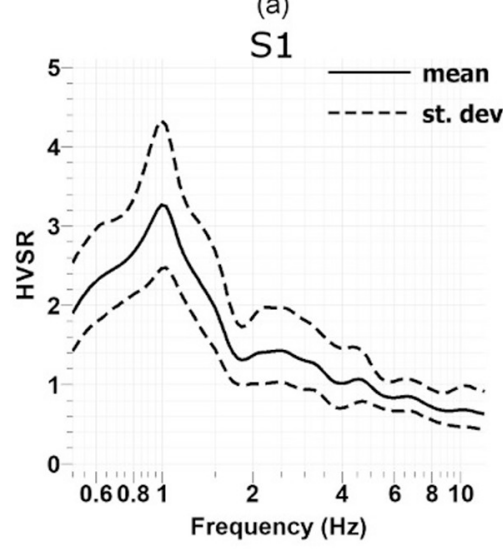

(d)

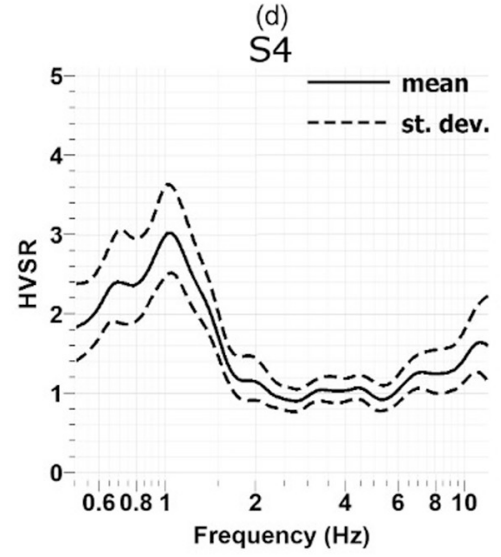

(b)

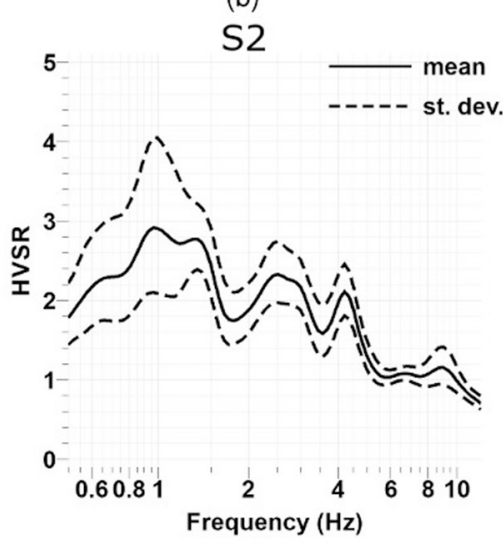

(e)

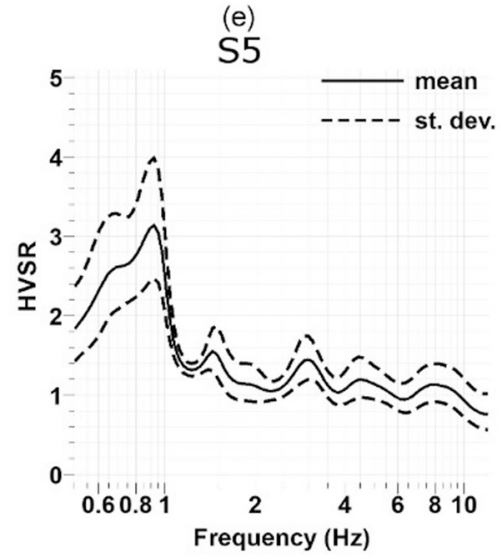

(c)

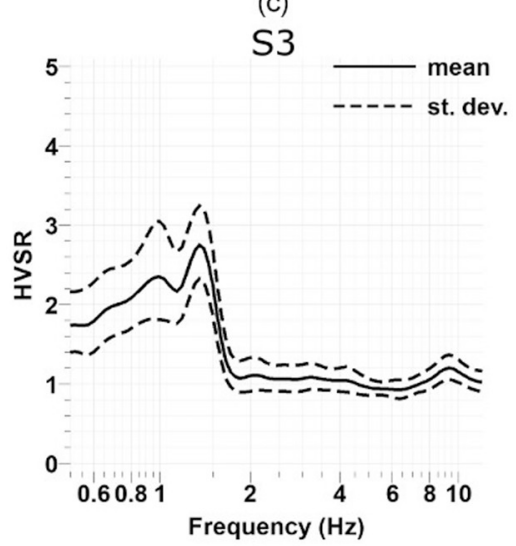

(f)

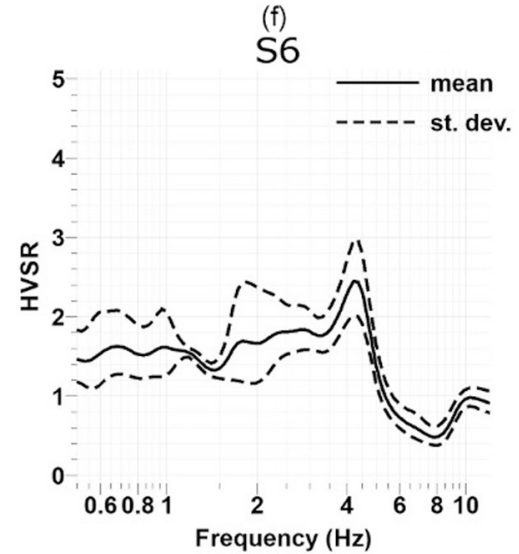

Fig. 5. Horizontal-to-vertical spectra of the six ambient-noise recordings: (a) S1, (b) S2, (c) S3, (d) S4, (e) S5 and (f) S6.

\subsubsection{Layered pyroclastites (PVF)}

The FA and paleosol layers of the PVF are both silty sands (25 and $30 \%$ of silt, respectively) with $<2 \%$ of gravel. The CA layers are coarse sands with $12 \%$ of gravel and $8 \%$ of silt. The L layers consist of gravel $(60 \%)$ with sand $(40 \%)$. Alteration did not result in formation of a noticeable amount of clay minerals.

Cyclic and dynamic tests were carried out at the average confinement stress expected in situ under the assumption of lithostatic conditions ( $\sigma_{v}^{\prime}=230 \mathrm{kPa}$ corresponding to $p^{\prime}=80 \mathrm{kPa}$ in the RC test). In specimens of the L lithotype, excessive signal attenuation prevents UPV measurements and grain size exceeds cyclic tests requirements. However, in this study, their dynamic behaviour was assimilated to that of CA layers, because the latter have the same density as well as similar grain size and mineralogical composition of the $\mathrm{L}$ layers. The variation of the normalized shear modulus $\left(G / G_{0}\right)$ with the shear strain amplitude $\left(\gamma_{c}\right)$ is reported in Fig. 9a together with the average curve for pumice sands found by Orense and Pender (2015). On the paleosol, on which all kind of tests were executed, the $G / G_{0^{-}} \gamma$ curves from DSDSS, $\mathrm{RC}$ and TS tests are in good agreement, but for sake of clarity only the curves from DSDSS are shown, being the investigated strain range wider. The value of small strain shear modulus $\left(G_{0}\right)$ obtained from the RC test is higher than that from DSDSS test, mainly due to the different stress state imposed (isotropic vs anisotropic).

\subsubsection{Stiff clay (CTF)}

The upper part of the deposit (depth $=0-10 \mathrm{~m}$ ) contains thin subhorizontal sandy laminae representing the $10 \%$ of the material, while the grain size composition of the underlying clay (clay $\sim 40 \%$, silt $\sim 55 \%$ and sand $<5 \%$ ) falls within the typical range of this formation (Tommasi et al., 2006).

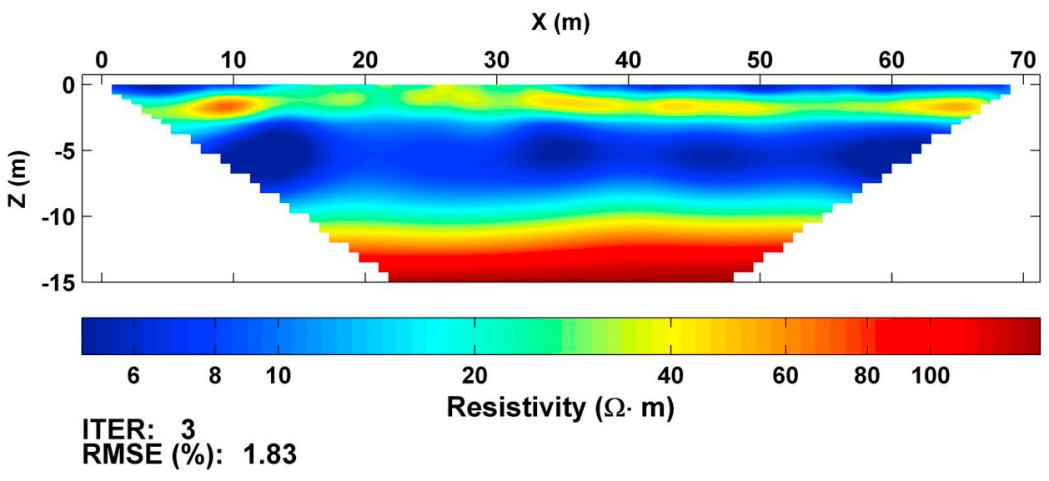

Fig. 6. ERT inverted model of the L1 line. 

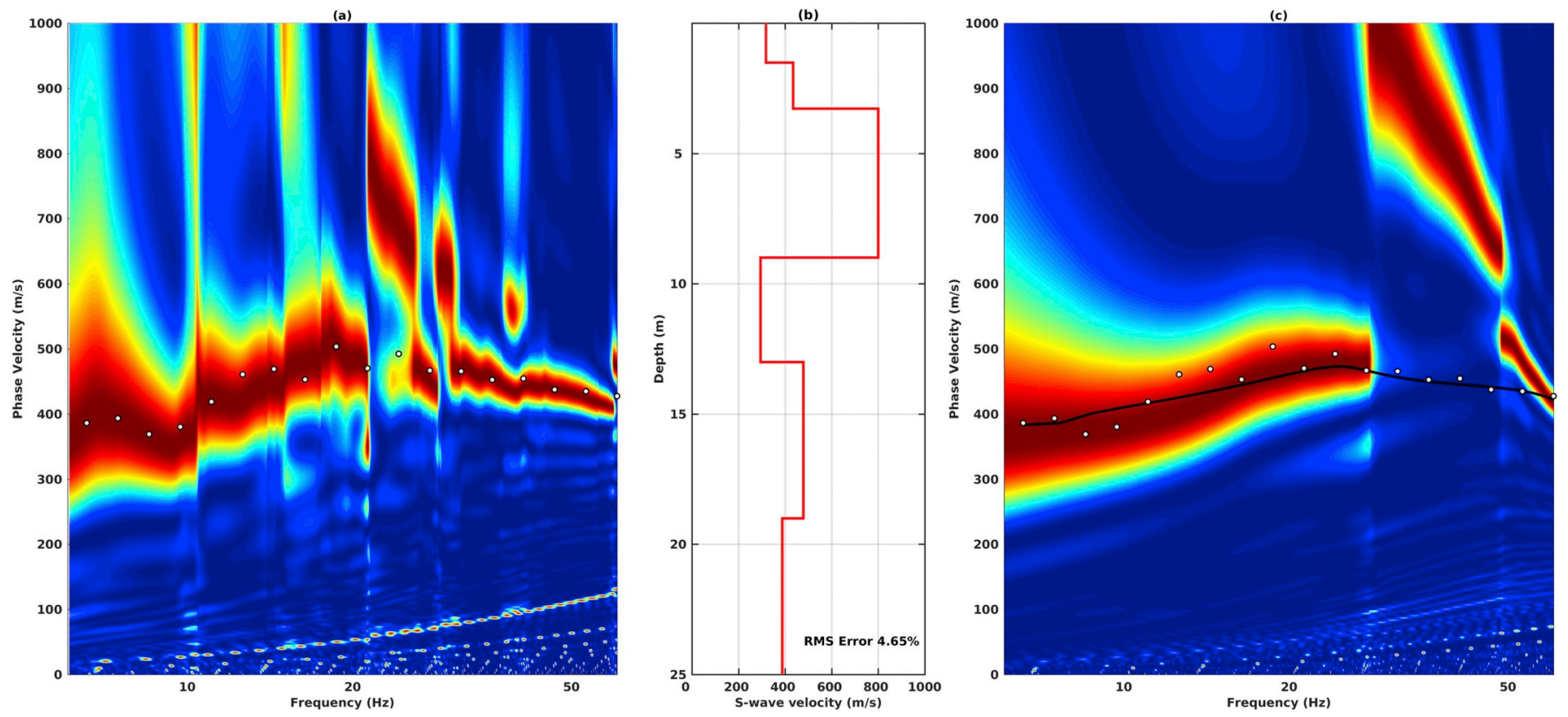

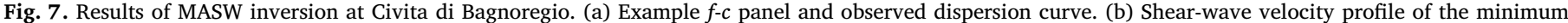
misfit inverted model. (c) A posteriori reflectivity modelling and comparison with observed (white open circles) and predicted (black line) modal dispersion.

The results of the dynamic and cyclic tests (double specimen DSDSS, $\mathrm{RC}$ and TS) performed on the CTF at the confinement stress expected on site $\left(\sigma_{v}^{\prime}=150-300 \mathrm{kPa}\right)$, are shown in Fig. $9 \mathrm{~b}$. Again, the $G_{O}$ values obtained from the RC test are higher than those from DSDSS test, while the relevant modulus reduction curves of the normalized shear modulus are in good agreement, so that only the DSDSS curve is shown. The curves are consistent with those expected for fine-grained soils with plasticity index of about 20\% (Vucetic and Dobry, 1991), displaying a (a)

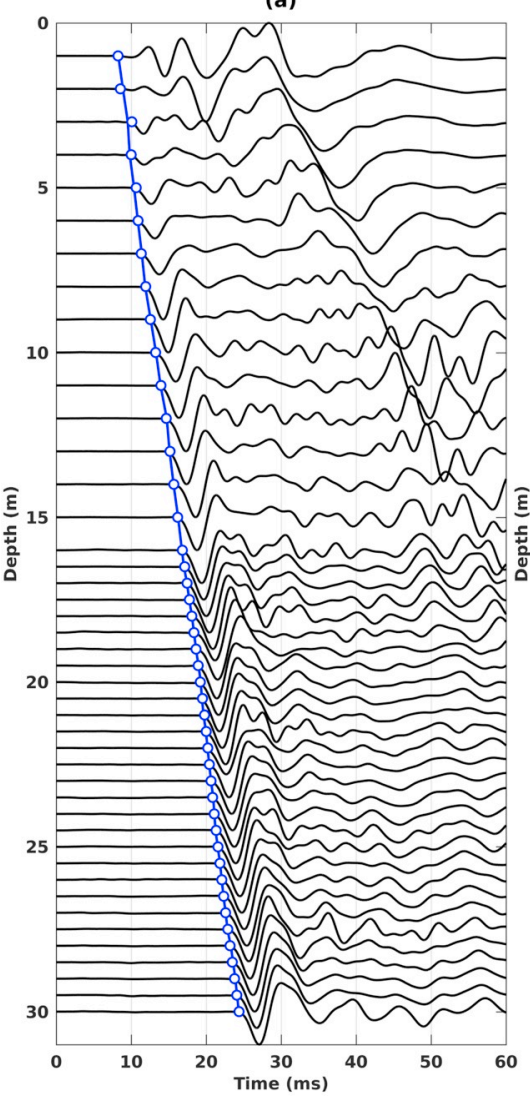

(b)

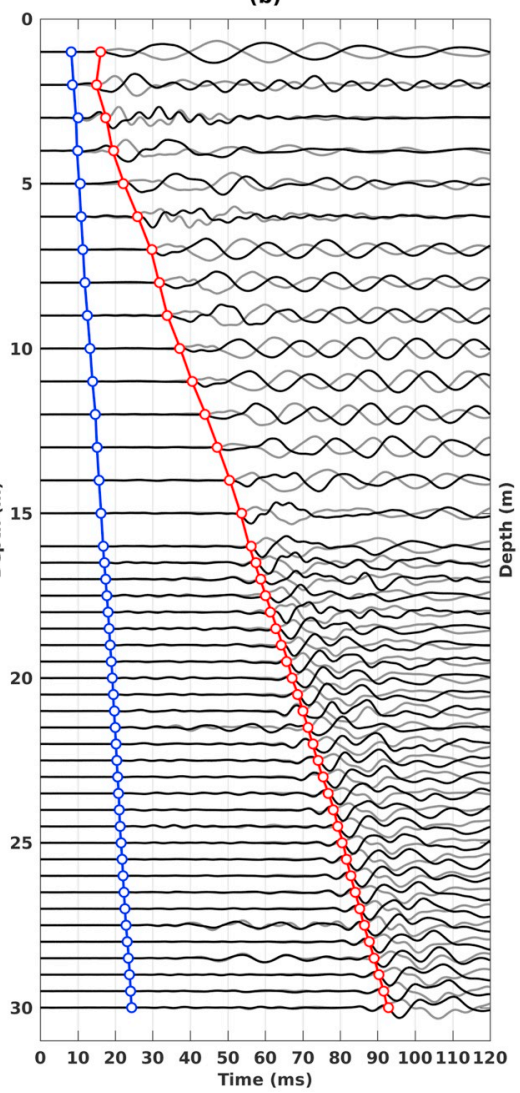

(c)

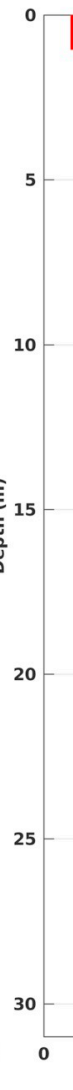

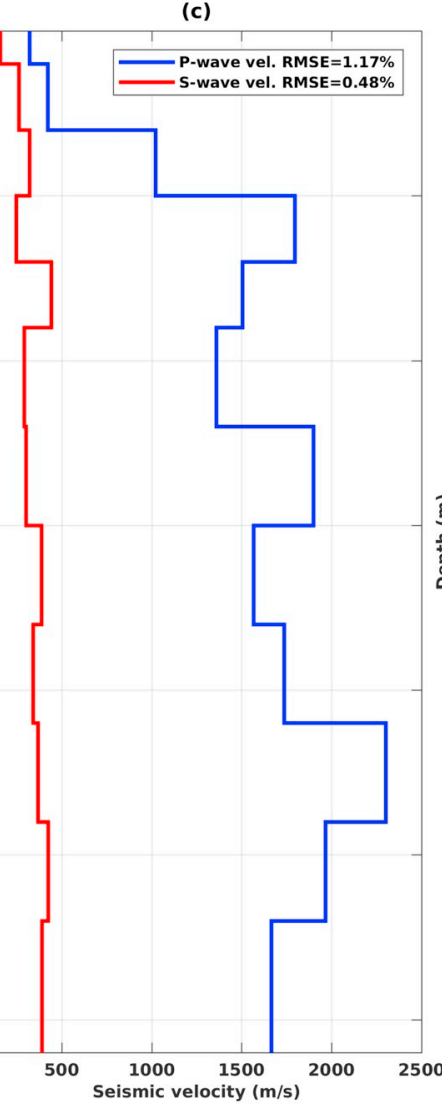

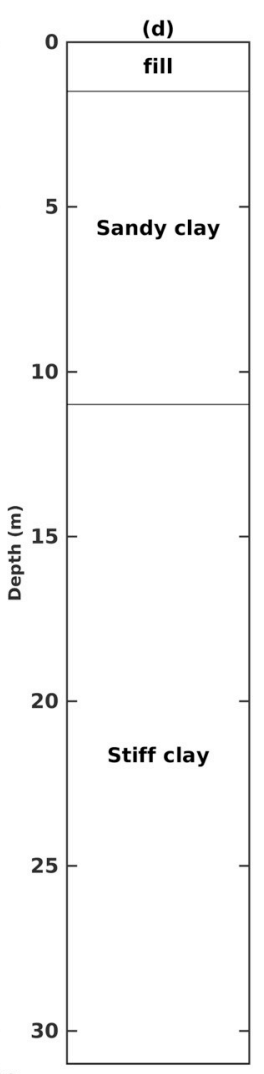

Fig. 8. Results of downhole investigations. (a) P-wave records with picked P-wave arrivals (blue line) on the vertical component. (b) S-wave records (two opposite polarities) with picked S-wave arrivals (red line) on the horizontal transverse component. (c) Inverted velocity profiles. P-wave (blue line) and S-wave (red line). The open white circles in (a) and (b) are the predicted traveltimes associated to these models. (For interpretation of the references to colour in this figure legend, the reader is referred to the web version of this article.) 
Table 3

Properties of the main geological units at Civita di Bagnoregio.

\begin{tabular}{|c|c|c|c|c|c|c|c|c|c|}
\hline MATERIAL & & $\rho_{s}\left(\mathrm{Mg} / \mathrm{m}^{3}\right)$ & $\rho\left(\mathrm{Mg} / \mathrm{m}^{3}\right)$ & $n\left[e_{0}\right]$ & $w(\%)$ & $\operatorname{Sr}(\%)$ & $V_{P}(\mathrm{~m} / \mathrm{s})$ & $\mathrm{V}_{\mathrm{S}}(\mathrm{m} / \mathrm{s})$ & $G_{O}(\mathrm{MPa})$ \\
\hline Ignimbrite $(I O B)^{\mathrm{a}}$ & & 2.34 & $1.10-1.38$ & $0.45-0.50$ & - & - & $1700^{\mathrm{e}}$ & $950^{\mathrm{e}}$ & $1100^{\mathrm{d}}, 900^{\mathrm{c}}$ \\
\hline \multirow[t]{4}{*}{ Layered pyroclastites (PVF) } & Cemented fine ash (FA) & 2.57 & $1.26-1.39$ & $0.53-0.58$ & 15.7 & 32 & 1090 & 650 & $600^{\mathrm{d}}, 340^{\mathrm{b}}$ \\
\hline & Coarse Ash (CA) & 2.50 & $0.94-1.01$ & 0.74 & 52 & 45 & 570 & 200 & $42^{\mathrm{d}}, 40^{\mathrm{c}}$ \\
\hline & Lapilli (L) & 2.50 & 1.04 & 0.69 & 33.6 & 38 & - & - & - \\
\hline & Paleosol & 2.51 & $1.77-1.86$ & $0.36-0.39$ & 16 & 68 & 1100 & 480 & $420^{\mathrm{d}}, 290^{\mathrm{b}}$ \\
\hline \multirow[t]{2}{*}{ Stiff clay (CVF) } & Stiff clay with sandy laminae & 2.67 & 2.05 & {$[0.62]$} & 22.5 & 100 & 1700 & 320 & $215^{\mathrm{d}}, 50^{\mathrm{b}}$ \\
\hline & Stiff clay & 2.70 & 2.04 & {$[0.65]$} & 25 & 100 & 1600 & 480 & $470^{\mathrm{d}}, 90^{\mathrm{b}}$ \\
\hline
\end{tabular}

a Orvieto site.

b DSDSS.

c RC.

d UPV.

e Reconstituted sample.

slightly higher nonlinearity of the silty clay in the upper portion of the deposit. Fig. 10 shows the log of clay fraction, Atterberg limits and resistance to pocket penetrometer measured on the cores along the vertical direction reported in Table 3 and compared to the DH results. The variability of P-wave velocity is well consistent to the resistance of the pocket penetrometer.

\section{Seismic response analysis}

The seismic response of the Civita hill was evaluated along the two main cross-sections (A-A' and B-B' in Fig. 1 and 2) using the 2D QUAD4M code (Hudson et al., 1994). QUAD4M is based on the Finite Element Method (FEM) and it performs a time-domain equivalent-

(a)
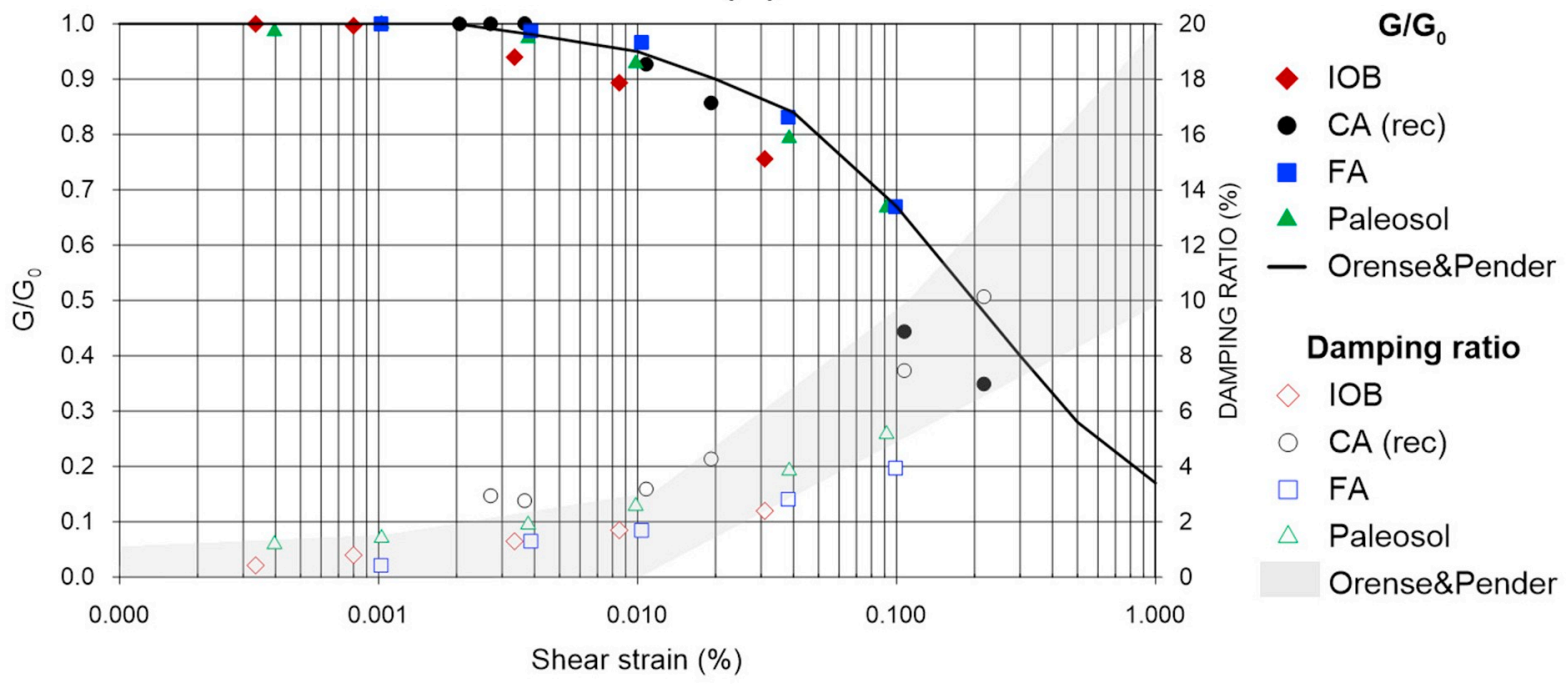

(b)

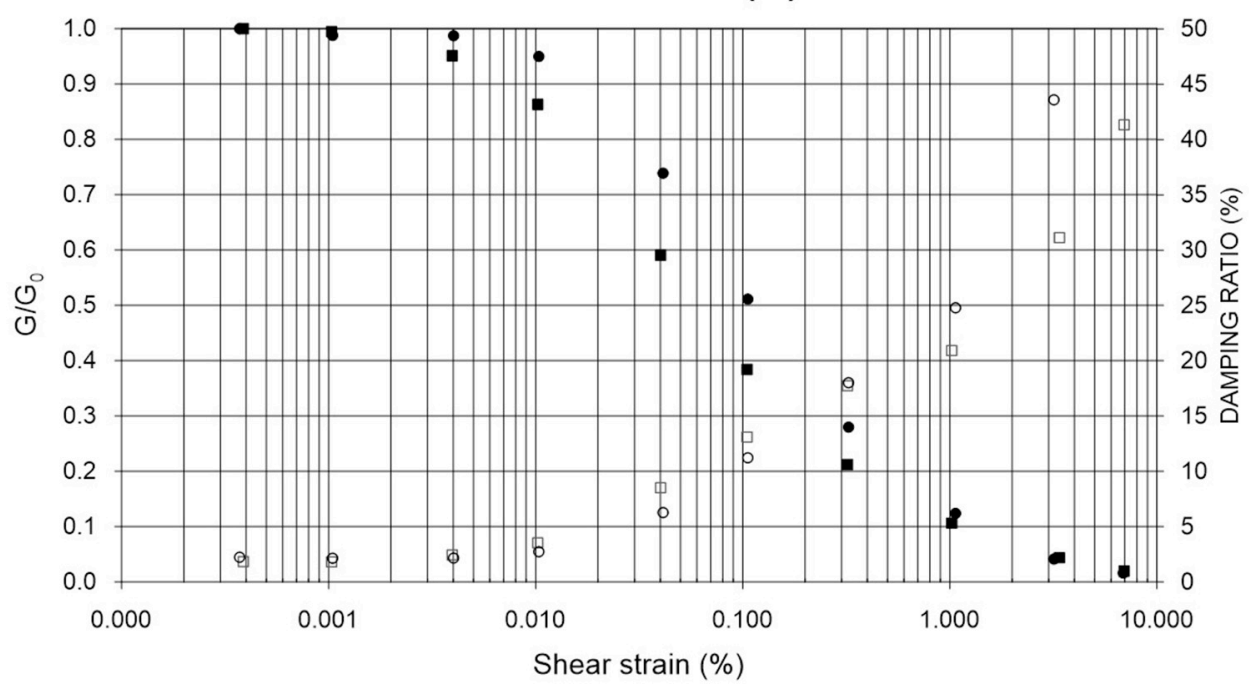

$\mathbf{G} / \mathbf{G}_{0}$

- Clay with sandy laminae

- Clay

Damping ratio

$\triangle$ Clay with sandy laminae

o Clay

Fig. 9. Normalized shear modulus $\left(G / G_{0}\right)$ and damping ratio $(D)$ versus cyclic shear strain amplitude $\left(\gamma_{c}\right)$ for (a) layered tuff $(P V F)$ and (b) stiff clay $(C T F)$. 


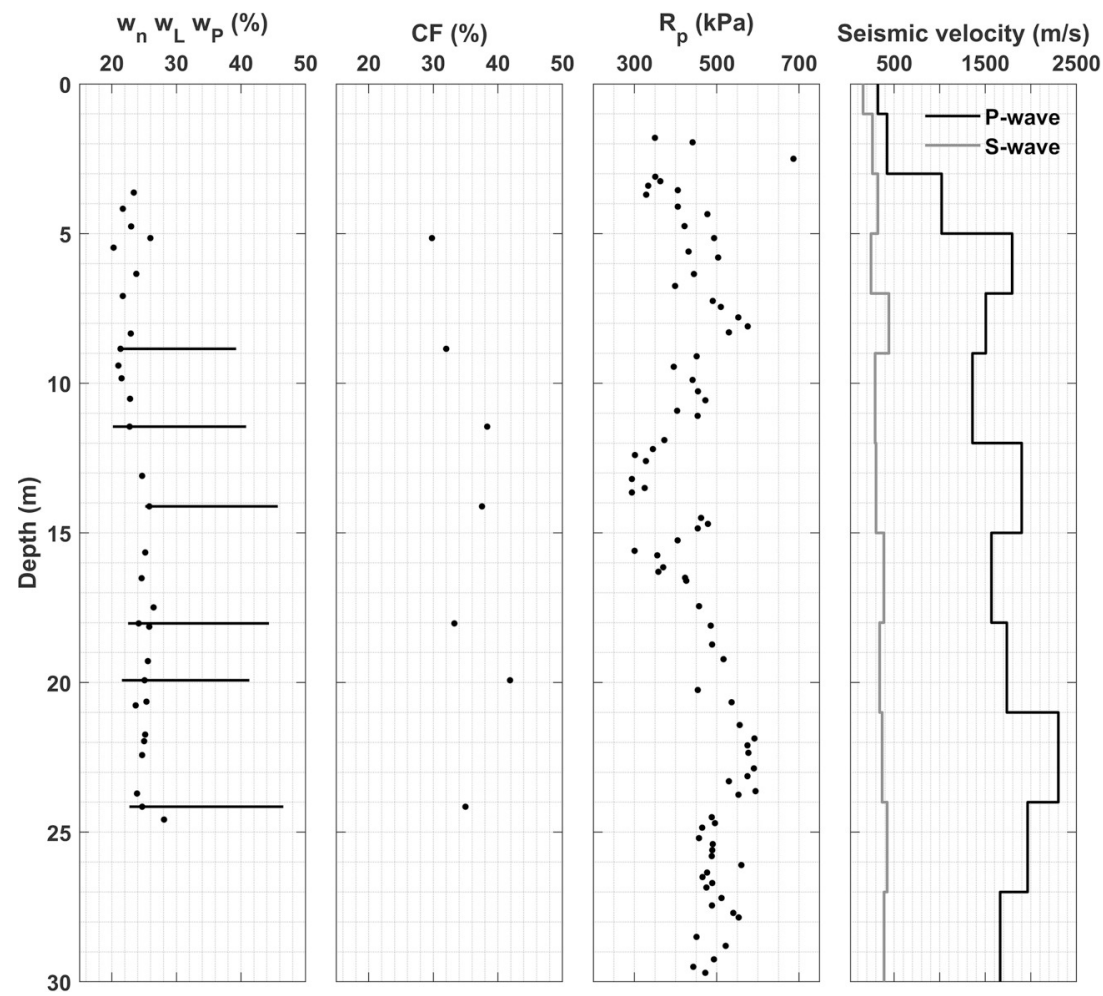

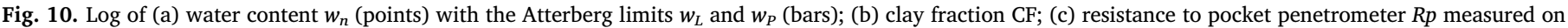
remoulded samples collected from borehole compared to the seismic velocity profiles (d).

linear simulation, incorporating a transmitting lower boundary in order to reduce ground motion overestimation due to the presence of a rigid boundary. The solution is achieved by a single-step time-domain integration and the nonlinear soil behavior is taken into account by modifying stiffness and damping ratio $(D)$ at each iteration. The convergence was achieved after five iterations.

A simplified geophysical and geotechnical model was set using the mean values obtained in the laboratory for the main parameters (Table 3 for density, P- and S-wave velocity), where equivalent values for the PVF were obtained according to Salamon (1968) and Gerrard (1982), as:

$\frac{1}{p^{e q}}=\sum_{i=1}^{N_{L}} \frac{f_{i}}{p_{i}}$

where $p$ is the parameter of interest (shear modulus and density in Table 3), $f$ the fraction of each layer $(55 \%, 30 \%$ and $15 \%$ assigned to fine ash, coarse ash/lapilli and paleosol respectively, based on drone images and direct inspections) and $N_{L}$ the number of layers (3). The resulting $V_{S}$ for layered tuff is around $375 \mathrm{~m} / \mathrm{s}$, which corresponds to the mean value observed on the MASW inverted model (Fig. 7b).

Seismic wave velocities of the clay formation were linearly increased, starting from the mean surface value for shallow clays $\left(V_{s}=400 \mathrm{~m} / \mathrm{s}, V_{p}=1500 \mathrm{~m} / \mathrm{s}\right)$ measured downhole (Fig. 8c). We assumed that down to the valley bottom (around $310-320 \mathrm{~m}$ a.s.l.) the increasing seismic wave velocities reach the maximum values of $600 \mathrm{~m} /$ $\mathrm{s}$ and $2300 \mathrm{~m} / \mathrm{s}$ respectively for $\mathrm{S}$ - and P-wave, which remain constant downwards. The maximum shear wave velocity is chosen according to the cross-hole measurements performed at the Orvieto hill (Cardarelli et al., 2002) on similar stiff clays.

The bedrock depth was fixed at $60 \mathrm{~m}$ a.s.l. (thickness of the clay formation around $300 \mathrm{~m}$ and $V_{\text {s, bedrock }}=1500 \mathrm{~m} / \mathrm{s}$ ) owing to the results of the aforementioned previous works. The resulting models for the two main cross-sections are depicted in Fig. 11a and b, and they were laterally extended $500 \mathrm{~m}$ far away from both sides in Fig. 11, in order to limit the spurious but unavoidable contribution due to reflections at the boundaries.

The FEM mesh was built using the open-source software Netgen (https://ngsolve.org/), employing triangular elements (Fig. 11c and $\mathrm{d}$ for A-A' and B-B' sections respectively). Since we were interested in modelling only the low-frequency behavior $(<5 \mathrm{~Hz}$ ), namely the $0.9-1.5 \mathrm{~Hz}$ amplification peaks displayed by the HVSR results, assuming a minimum shear wave velocity $V_{S}{ }^{\mathrm{min}}=375 \mathrm{~m} / \mathrm{s}$ (layered tuff), the maximum mesh size $d^{\max }$ was fixed as (Kuhlemeyer and Lysmer, 1973):

$d^{\max }=\frac{V_{S}^{\min }}{8 f^{\max }} \cong 9.5 \mathrm{~m}$

The input motion was selected on the Regional database for microzonation (http://www.regione.lazio.it/prl_ambiente/?vw = contenutidettaglio\&id $=219$ ) for the Municipality of Bagnoregio with PGA = $0.1443 \mathrm{~g}$. The motion was applied directly as "outcropping" motion, and internally the program modified it in order to be applied at the base of the model for simulating a deformable (elastic) bedrock.

We performed two different seismic response analyses. In the first one we considered a linear viscoelastic model for the subsoil, considering a constant ratio of $G / G_{O}=1$ versus $\gamma_{c}$ as well as a constant damping ratio, equal to $3 \%$ for the soil layers (approximately the maximum-strain value measured in the soil column, within the pyroclastic deposits) and to $0.5 \%$ for the seismic bedrock. In the second one, we carried on a complete nonlinear seismic response analysis, employing the dynamic parameters retrieved by laboratory testing.

The $G / G_{0-\gamma_{c}}$ and $D-\gamma_{c}$ curves measured for the predominant fine ash component (blue filled and empty squares in Fig. 9a) were assigned to the $P V F$, while the clay formation was modelled discarding the values obtained for the minor sandy clay layer.

The linear analysis is theoretically more suitable to compare the peak frequency of the transfer function to the main resonant peak of the microtremor analysis. On the other hand, the nonlinear analysis is intended to produce more realistic results, as far as the acceleration values increase. 

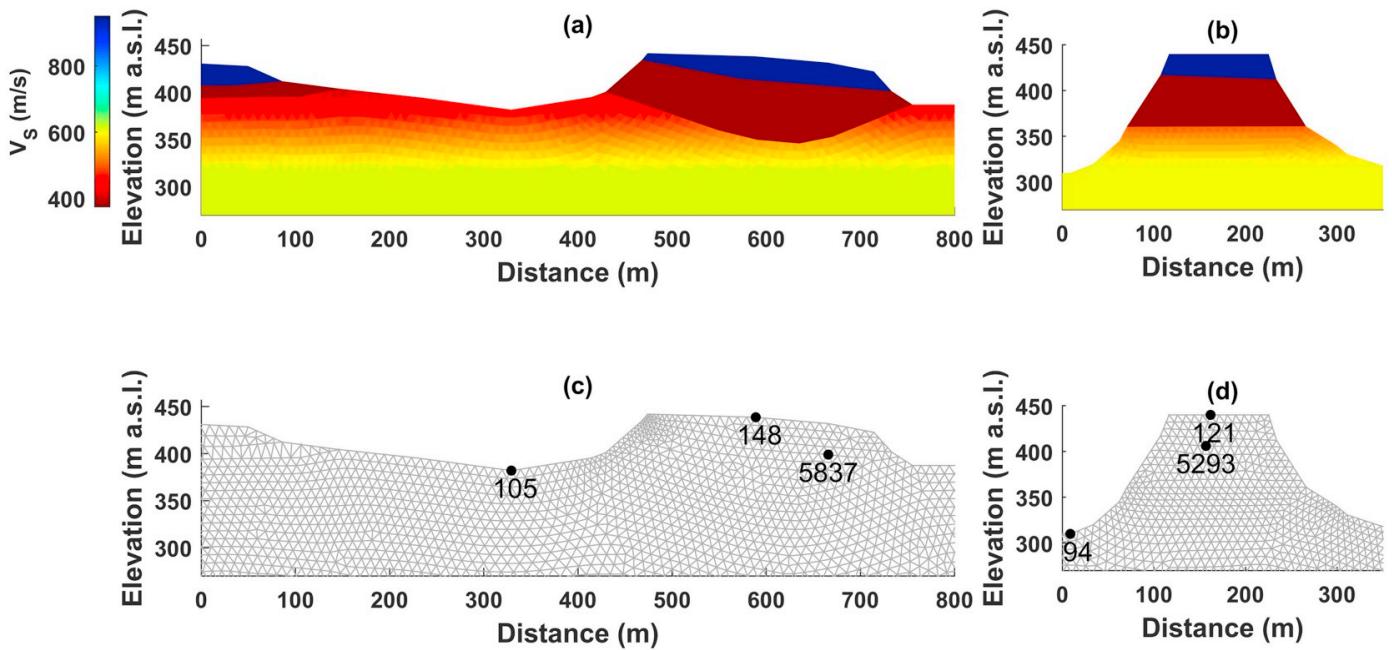

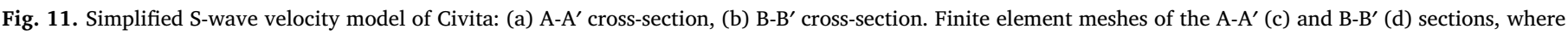

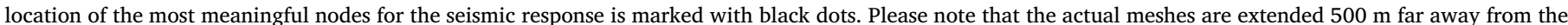
side boundaries and down to a depth of $60 \mathrm{~m}$ a.s.1.

The results of the 2D seismic response analyses are shown in Fig. 12 (A-A' section) and 13 (B-B' section) where we compare the response spectra and the amplification functions for the two seismic response analysis (linear and nonlinear), computed for the most meaningful nodes (see Fig. 2 for their location), at the top of the hill (Fig. 12b,e and $13 \mathrm{~b}, \mathrm{e})$, at the top of the $P V F$ where the tunnel passes throughout the hill (Fig.12c,f and 13c,f) and on the clay saddle (Fig. 12a,d and 13a,d).

It can be noticed that in this case the nonlinear effect is not particularly relevant, mostly because of the limited value of the PGA. Little discrepancy between the two analyses occurs in the B-B' section especially for the node no. 121 located at the top of the hill. The peak amplification obtained in the linear analyses is slightly less than the non-linear (linear-equivalent) one because of the constant damping value of $3 \%$ selected for all the formations in the linear analysis, which is slightly greater than the maximum damping appearing in the non linear analysis. Such value was selected to avoid very large amplifications in the linear case.

At the top of the hill, the amplification function for both sections shows a main resonant frequency around $1 \pm 0.1 \mathrm{~Hz}$, comparable to that retrieved by the HVSR method (Fig. $5 \mathrm{a}, \mathrm{b}$ and e). The amplification is much higher in the $\mathrm{B}^{\mathrm{B}} \mathrm{B}^{\prime}$ section (maximum value around 8 at $0.9 \mathrm{~Hz}$ ) likely due to the peculiar morphology (steep slopes), than those calculated in the A-A' section (around 5 at $1.1 \mathrm{~Hz}$ ). The resonant frequency deviations can be due to the different morphology of the two crosssections. The seismic response below the tunnel $(P V F)$ is comparable to that of the hill, with lower amplifications, as previously seen on ambient noise recordings. Over the clay saddle, we obtained a nearly flat amplification function in agreement with the H/V spectra.

\section{Discussion}

This case study highlights the potential of an integrated experimental approach for complementing the advantages of different techniques, thus reducing the uncertainty associated on the final geophysical and geotechnical model. In this respect MASW data, although capable to explore deeper than electrical tomography, have too low resolution in depicting lateral variations. Conversely, ERT suffers of a loss of resolution at greater depths but it displays high-resolution for near-surface anomalies. Nevertheless, in this specific case, both methods enlightened the great heterogeneity of the layered pyroclastites, which mainly results from lithological variations due to both genetic and epigenetic process.

However, surface geophysical methods cannot be applied as a standalone but they are to be complemented by downhole and laboratory investigations, which help to define the dynamic properties of the different lithotypes. Therefore, this work stressed out that an integrated preliminary characterization performed both using field and laboratory measurements is preparatory for the subsequent modelling phase. However, in case of complex lithological units (i.e. layered pyroclastites), simplifications were introduced to the geotechnical model carried out through laboratory tests, to serve as input of a wellestablished 2D FEM code for seismic response analysis. For the same reason of reproducibility, we decided to use the strong motions provided by the Regional Authority. A site-specific near-source seismological study, though beyond the scope of this paper, may be the subject of future development of the research. Finally, despite a complete 3D simulation would better describe the complex behaviour of the seismic response at this site, the results of the $2 \mathrm{D}$ analysis represent a necessary step in the comprehension of the amplification phenomena occurring at Civita, which will serve as a basis for future development of investigation and modelling of the seismic response of the hill.

In this sense, the 2D seismic response of Civita was early investigated by Paolucci (2002), under the hypotheses of homogenous hill, with a constant value of $V_{s}=600 \mathrm{~m} / \mathrm{s}$ and a visco-elastic linear constitutive soil model. He obtained an amplification function with a main peak around $1 \mathrm{~Hz}$ and a maximum of the amplification function at the top of the hill (2.5). However, we demonstrated that the clayey and pyroclastic materials forming the hill of Civita di Bagnoregio are highly heterogeneous, as already pointed out by previous works (Sciotti et al., 1997; Garbin et al., 2013; Margottini and Di Buduo, 2017). The strong variability of the elastic properties of the layered pyroclastites is also associated to an inversion of the normal increase of velocity with depth. This has an impact on the seismic response of the hill, mainly governing the secondary peak appearing at higher frequencies (around $1.5 \mathrm{~Hz}$ ) only at the nodes located within the tunnel (Fig. 12f and 13f) and not on surface (Fig. 12e and 13e). In fact, the main resonant frequency achieved on both sections $(1 \pm 0.1 \mathrm{~Hz})$ is comparable to the one obtained by Paolucci (2002) using a homogenous model, while the amplification maxima reached on our models are much higher. These discrepancies are likely due to a joint effect of both topography and complex lithostratigraphy, the latter not considered in the work of Paolucci (2002). For this particular case study, the non-linear behavior of the seismic response is not much emphasized at moderate seismicity as it shoud be more relevant fore more severe shaking scenarios.

Currently, a residual limitation on the accuracy of the seismic response analysis is due to the bedrock depth, which has been estimated by previous researchers (e.g. Mancini et al., 2004) with a confidence interval of hundred meters. 
(a)

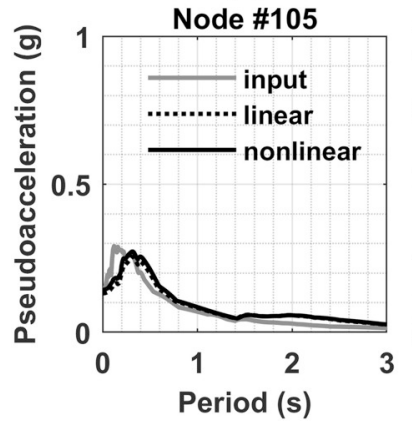

(d)

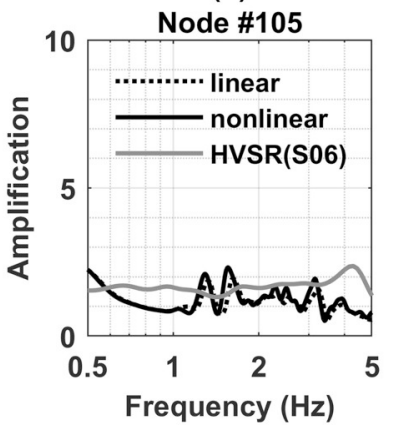

(b)

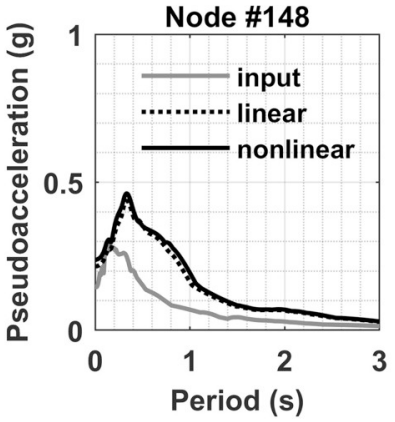

(e)

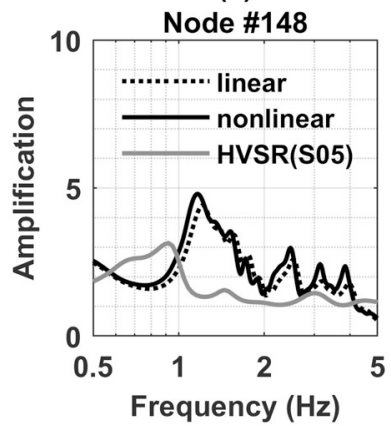

(c)

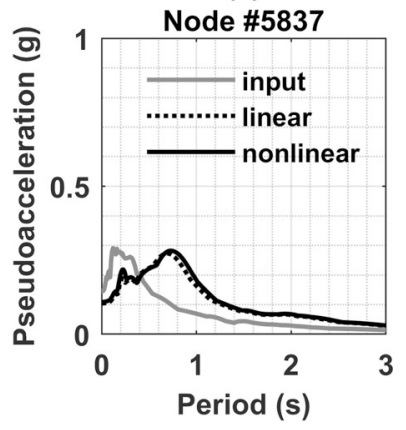

(f)

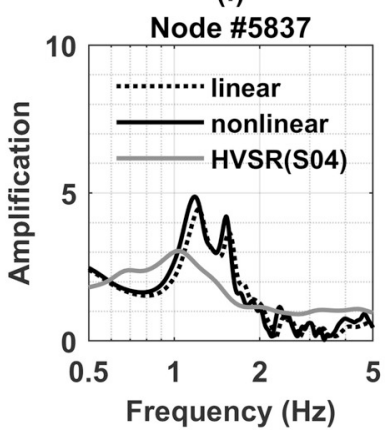

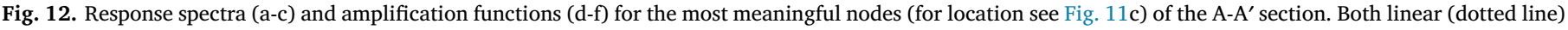
and nonlinear (solid line) analyses are compared to the ambient noise recordings on selected stations.

\section{Conclusions}

This paper is mainly focused on the definition of the subsoil model for the seismic response analysis of a typical geomorphological situation encountered in many historical centres in Central Italy, built on a volcanic plateau resting on deformable sublayer. The complexity of the geological and morphological conditions as well as the peculiarity of the geotechnical and geophysical properties of the materials involved makes a challenging problem to deal with.

The integration of different investigation techniques was capable of circumventing the logistic limitations imposed by the historical center, which are a potential source of over-simplified geophysical and geotechnical models, and the poorly estimated seismic properties, thus resulting in unrealistic seismic response estimates. (a)

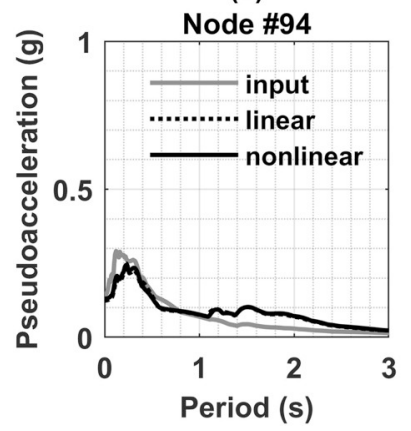

(d)

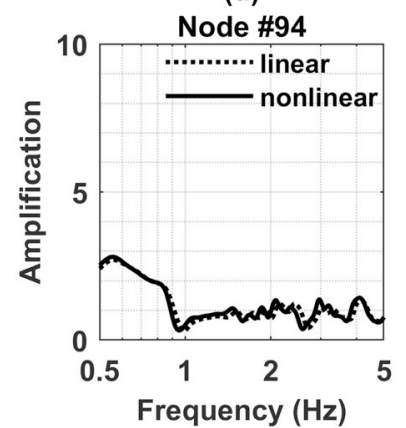

(b)

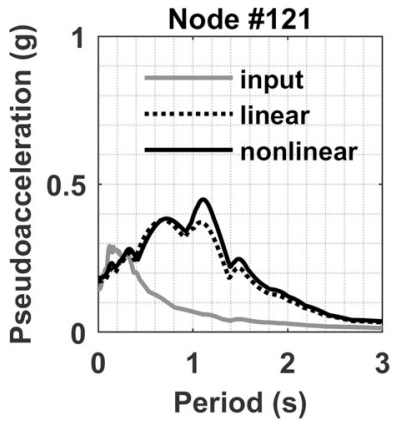

(e)

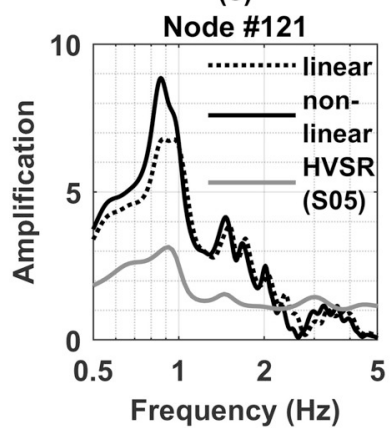

(c)

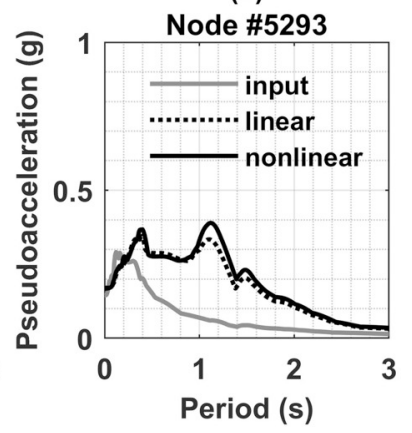

(f)

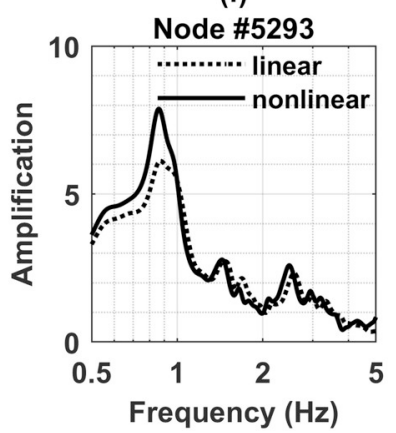

Fig. 13. Response spectra (a-c) and amplification functions (d-f) for the most meaningful nodes (for location see Fig. 11d) of the B-B' section. Both linear (dotted line) and nonlinear (solid line) analyses are compared to the ambient noise recordings on selected stations. 
For the first time, the geological units forming the Civita di Bagnoregio hill have been fully characterized in terms of dynamic properties for seismic response analyses as per Table 3.

The seismic response analysis indicates that the stiff ignimbrite slab at the hill top does not play a significant role in seismic response, as well as small-scale variations of acoustic impedance within the layered pyroclastites. The assumption of a deep seismic bedrock is supported by the correspondence between the frequency of the main amplification peaks and the experimental values of resonant frequency of the passive microtremor measurements.

\section{Declaration of Competing Interest}

The authors declare that they have no known competing financial interests or personal relationships that could have appeared to influence the work reported in this paper.

\section{Acknowledgements}

This research is supported by "Sapienza" University of Rome grant 2015 no. C26H15HTB2, entitled "Civita di Bagnoregio: envisioning a sustainable future": P.I. Prof. Giovanni Attili. Dr. Giovanni Maria di Buduo of the Museum of Landslides at Civita di Bagnoregio is greatly acknowledged for his assistance in the field and in programming in-situ investigations. Thanks are due to Maurizio De Biase, Silvano Silvani and Francesco Stelitano for their assistance in laboratory testing. Francesco Pugliese and M.Sc. student Lavinia Vulpiani ("Sapienza" University of Rome) are thanked for their technical support to the on-site geophysical measurements.

\section{References}

Bonnefoy-Claudet, S., Cornou, C., Bard, P.Y., Cotton, F., Moczo, P., Kristek, J., Fäh, D., 2006. H/V ratio: a tool for site effects evaluation. Results from 1-D noise simulations. Geophys. J. Int. 167 (2), 827-837.

Cappelletti, P., Langella, A., Colella, A., de Gennaro, R., 1999. Mineralogical and technical features of zeolite deposits from northern Latium volcanic district. Periodico di Mineralogia 68 (2), 127-144.

Cardarelli, E., Bernabini, M., Tommasi, P., 2002. P and S waves cross-hole surveys, characterization of the Orvieto hill formations. SEG Tech. Program Expanded Abstr. 1468-1471.

Cardarelli, E., Cercato, M., de Nardis, R., Di Filippo, G., Milana, G., 2008. Geophysical investigations for seismic zonation in municipal areas with complex geology: the case study of Celano, Italy. Soil Dyn. Earthq. Eng. 28, 950-963.

Cardarelli, E., Cercato, M., De Donno, G., 2014a. Characterization of an earth-filled dam through the combined use of electrical resistivity tomography, P-and SH-wave seismic tomography and surface wave data. J. Appl. Geophys. 106, 87-95.

Cardarelli, E., Cercato, M., De Donno, G., Di Filippo, G., 2014b. Detection and imaging of piping sinkholes by integrated geophysical methods. Near Surf. Geophys. 12 (3), 439-450.

Cercato, M., 2011. Global surface wave inversion with model constraint. Geophys. Prospect. 59, 210-226.

Cercato, M., Cara, F., Cardarelli, E., Di Filippo, G., Di Giulio, G., Milana, G., 2010. Shearwave velocity profiling at sites with high stiffness contrasts: a comparison between invasive and non-invasive methods. Near Surf. Geophys. 8, 75-94.

Cevolani, F., Del Gizzo, M., Quattrocchi, F., Serafini, S., 1990. Caratteristiche geotecniche delle argille di base nell'area di Civita di Bagnoregio. In: Civita di Bagnoregio: osservazioni geologiche e monitoraggio storico dell'ambiente: una ricerca ENEA. Associazione Progetto Civita, Roma, pp. 44-46.

Costanzo, A., d'Onofrio, A., Lanzo, G., Pagliaroli, A., Penna, A., Puglia, R., Santucci De Magistris, F., Sica, S., Silvestri, F., Tommasi, P., 2007. Seismic response of historical centers in Italy: selected case studies. In: Workshop on "Geotechnical Earthquake Engineering related to Monuments and Historical Centers", Proc. IVICEGE, Thessaloniki, pp. 319-342.

Dahlin, T., Zhou, B., 2004. A numerical comparison of 2D resistivity imaging with 10 electrode arrays. Geophys. Prospect. 52 (5), 379-398.

De Donno, G., Cardarelli, E., 2017. VEMI: a flexible interface for 3D tomographic inversion of time- and frequency-domain electrical data in EIDORS. Near Surf. Geophys. 15, 43-58.

D'Elia, B., Lanzo, G., Pagliaroli, A., 2003. Small-strain stiffness and damping of soils in a direct simple shear device. In: Proceedings of the 2003 Pacific Conference on
Earthquake Engineering, Christchurch, New Zealand, paper n. 111. New Zealand National Society for Earthquake Engineering, Wellington, New Zealand.

Garbin, F., Margottini, C., Brancaleoni, R., Sonnessa, A., 2013. Softening and swelling mechanism affecting south slope of Civita di Bagnoregio (VT). In: Bilotta, E., Flora, A., Lirer, S., Viggiani, C. (Eds.), Geotechnical Engineering for the Preservation of Monuments and Historic Sites. CRC Press.

Gerrard, C.M., 1982. Equivalent elastic moduli of a rock mass consisting of orthorhombic layers. In: International Journal of Rock Mechanics and Mining Sciences \& Geomechanics Abstracts (Vol. 19, No. 1, pp. 9-14), Pergamon.

Hudson, M., Idriss, I.M., Beikae, M., 1994. QUAD4M: a computer program to evaluate the seismic response of soil structures using finite element procedures and incorporating a compliant base. In: Center for Geotechnical Modeling, Department of Civil and Environmental Engineering. University of California, Davis.

Iacurto, O., Priori, A., 1995. Caratterizzazione geomeccanica delle ignimbriti compatte di Civita di Bagnoregio (VT) in situazioni di dissesto idrogeologico. Geologia tecnica e ambientale 2, 35-51.

Isenhower, W.M., 1979. Torsional Simple Shear/Resonant Column Properties of San Francisco Bay mud. MSc Thesis. The University of Texas at Austin, TX, USA.

Kuhlemeyer, R.L., Lysmer, J., 1973. Finite element method accuracy for wave propagation problems. J. Soil Mech. Found. Div 99 (Tech. Rpt.).

Lane, J.W., White, E.A., Steele, G.V., Cannia, J.C., Williams, J.H., 2008. Estimation of bedrock depth using the horizontal-to-vertical (H/V) ambient-noise seismic method. In: 14th EAGE European Meeting of Environmental and Engineering Geophysics, 15-17 September, Kraków, Poland.

Mancini, M., Girotti, O., Cavinato, G.P., 2004. Il pliocene e il quaternario della media Valle del Tevere (Appennino centrale). Geol. Romana 37, 175-236.

Margottini, C., 1988. Evoluzione morfologica del colle di Civita di Bagnoregio in tempi storici. In: Lattanzi, F., Polci, S. (Eds.), L'ambiente la memoria, il progetto - testimonianze su Civita di Bagnoregio. Sugar Edizioni, Roma, pp. 51-88.

Margottini, C., Di Buduo, G.M., 2017. The Geological and Landslides Museum of Civita di Bagnoregio (Central Italy). Landslides 14, 435-445.

Nakamura, Y., 1989. A method for dynamic characteristics estimation of subsurface using microtremor on the ground surface. Railway Technical Research Institute, Quarterly Reports 30 (1).

Napoleoni, Q., 1991. Civita di Bagnoregio: un esempio di recupero. "L'Ingegnere", Ingegneria Ambientale e Territoriale 5-8, 99-111.

Nappi, G., Antonelli, F., Coltorti, M., Milani, L., Renzulli, A., Siena, F., 1998. Volcanological and petrological evolution of the Eastern Vulsini District, Central Italy. J. Volcanol. Geotherm. Res. 87, 211-232.

Orense, R.P., Pender, M.J., 2015. From micro to macro: an investigation of the geomechanical behaviour of pumice sand. Volcanic Rocks and Soils 45.

Paolucci, R., 2002. Amplification of earthquake ground motion by steep topographic irregularities. Earthq. Eng. Struct. Dyn. 31, 1831-1853.

Park, C.B., 2013. MASW for geotechnical site investigation. Lead. Edge 32 (6), 656-662.

Park, C.B., Miller, R.D., Xia, J., 1999. Multichannel analysis of surface waves. Geophysics 64, 800-808.

Salamon, M.D.G., 1968. Elastic moduli of a stratified rock mass. In: International Journal of Rock Mechanics and Mining Sciences \& Geomechanics Abstracts (Vol. 5, No. 6, pp. 519-527), Pergamon.

Samouëlian, A., Cousin, I., Tabbagh, A., Bruand, A., Richard, G., 2005. Electrical resistivity survey in soil science: a review. Soil Tillage Res. 83 (2), 173-193.

Sciotti, M., 1980. Fattori geologici ed antropici nei problemi di stabilità di antichi centri abitati dell'Italia centrale. Associazione Geotecnica Italiana-XIV Convegno Nazionale di Geotecnica 3, 85-89.

Sciotti, M., Focardi, P., Margottini, C., Ogliotti, C., Serafini, S., 1997. Civita di Bagnoregio: a town in decline. In: Viggiani, C. (Ed.), Geothecnical Engineering for the Preservation of Monuments and Historic Sites. Taylor \& Francis Group, London, pp. 819-827 (ISBN: 9789054108719).

SESAME Project, 2004. Deliverable D23.12, Guidelines for the implementation of the H/V spectral ratio technique on ambient vibrations measurements, processing and interpretation. available from the website. http://sesame-fp5.obs.ujf-grenoble.fr/Papers/ HV User Guidelines.pdf.

Socco, L.V., Strobbia, C., 2004. Surface-wave method for near-surface characterization: a tutorial. Near Surf. Geophys. 2, 165-185.

Tommasi, P., Ribacchi, R., 1998. 1998. Mechanical behaviour of the Orvieto tuff. In: Evangelista, A., Picarelli, L. (Eds.), The Geotechnics of Hard Soils-Soft Rocks, Proc. 2nd Int. Symp. On Hard Soils-Soft Rocks, Naples, Italy, October1998. 2. Balkema, Rotterdam, pp. 901-909.

Tommasi, P., Pellegrini, P., Boldini, D., Ribacchi, R., 2006. Influence of rainfall regime on hydraulic conditions and movement rates in the overconsolidated clayey slope of the Orvieto hill (Central Italy). Can. Geotech. J. 43 (1), 70-86. https://doi.org/10.1139/ T05-081.

Tommasi, P., Verrucci, L., Rotonda, T., 2015. Mechanical properties of a weak pyroclastic rock and their relationship with microstructure. Can. Geotech. J. 52 (2), 211-223. https://doi.org/10.1139/cgj-2014-0149.

Verrucci, L., Lanzo, G., Tommasi, P., Rotonda, T., 2015. Cyclic and dynamic behaviour of a soft pyroclastic rock. Geotechnique 65, 359-373. https://doi.org/10.1680/geot. SIP.15.P.012.

Vucetic, M., Dobry, R., 1991. Effect of soil plasticity on cyclic response. J. Geotech. Eng. 117 (1), 89-107. 